\title{
Targeting HIF-1 $\alpha$ Function in Cancer through the Chaperone Action of NQO1
}

\author{
Eduardo Salido', David J. Timson ${ }^{2}$, Isabel Betancor-Fernández ${ }^{1}$, Rogelio Palomino-Morales ${ }^{3}$ and \\ Angel L. Pey ${ }^{4}$ * \\ 1 Centre for Biomedical Research on Rare Diseases (CIBERER), Hospital Universitario de Canarias, Tenerife, \\ Spain.; esalido@ull.es (E.S.); ibetfer3@gmail.com (I.B.-F.). \\ 2 School of Pharmacy and Biomolecular Sciences, The University of Brighton, Brighton, BN2 4GJ. UK; \\ D.Timson@brighton.ac.uk. \\ 3 Department of Biochemistry and Molecular Biology I, Faculty of Sciences and Biomedical Research Center \\ (CIBM), University of Granada, Granada, Spain; rpm@ugr.es. \\ 4 Department of Physical Chemistry and Unit of Excellence in Chemistry, University of Granada, Granada, \\ Spain. \\ * Correspondence: angelpey@ugr.es; Tel.: +34-958240173.
}

\begin{abstract}
HIF-1 $\alpha$ is a master regulator of oxygen homeostasis involved in different stages of cancer development. Thus, HIF-1 $\alpha$ inhibition represents an interesting target for anti-cancer therapy. It was recently shown that HIF-1 $\alpha$ interaction with NQO1 inhibits its proteasomal degradation, thus suggesting that targeting the stability of NQO1 could led to destabilization of HIF-1 $\alpha$ as a therapeutic approach. Since the molecular interactions of NQO1 with HIF-1 $\alpha$ are beginning to be unraveled, we review here our current knowledge on the intracellular functions and stability of NQO1, its pharmacological modulation by small ligands, and the molecular determinants of its roles as a chaperone of many different proteins including cancer-associated factors such as p53 and p73 $\alpha$. This knowledge is then discussed in the context of potentially targeting the intracellular stability of HIF- $1 \alpha$ by acting on its chaperone, NQO1. This could result in novel anti-cancer therapies.
\end{abstract}

Keywords: HIF-1 $\alpha$;NQO1; hypoxia; angiogenesis; cancer; protein:protein interactions; ligand binding; proteasomal degradation

\section{HIF-1 $\alpha$ : structure, function, regulation and disease}

Oxygen homeostasis is one of the main principles of life for most organisms, especially metazoa. The availability of oxygen regulates many physiological processes that are strictly controlled by a complex network of molecules in the organism. In metazoa, the master transcription factor that supervises this regulatory network is the Hypoxia-induced factor 1 (HIF-1). HIF-1 regulates the expression of a multitude of genes in response to oxygen availability and plays a fundamental role in many physiological and pathological processes [1,2].

\subsection{HIF-1 $\alpha$ structure and function}

HIF-1 is a DNA-binding complex composed of two subunits ( $\alpha$ and $\beta$ ), both basic helix-loop-helix (bHLH) proteins of the PER-ARNT-SIM (PAS) family. HIF-1 $\beta$ (initially named aryl hydrocarbon nuclear receptor translocator, ARNT) is constitutively expressed, and thus, its expression and activity are oxygen-independent. In contrast, HIF-1 $\alpha$ is strongly repressed in normoxia and induced in hypoxia [3]. In response to low oxygen, both subunits of HIF-1 $\alpha$ dimerize, and HIF-1 binds to the hypoxia response element (HRE) of the promoter or enhancer region of the target genes to induce transcription. HIF-1 induces the transcription of numerous genes $[4,5]$ 
involved in many biological processes, such as angiogenesis, erythropoiesis, anaerobic metabolism, cell survival, and cell proliferation. Thus, it is crucial for cancer development (see Section 1.3).

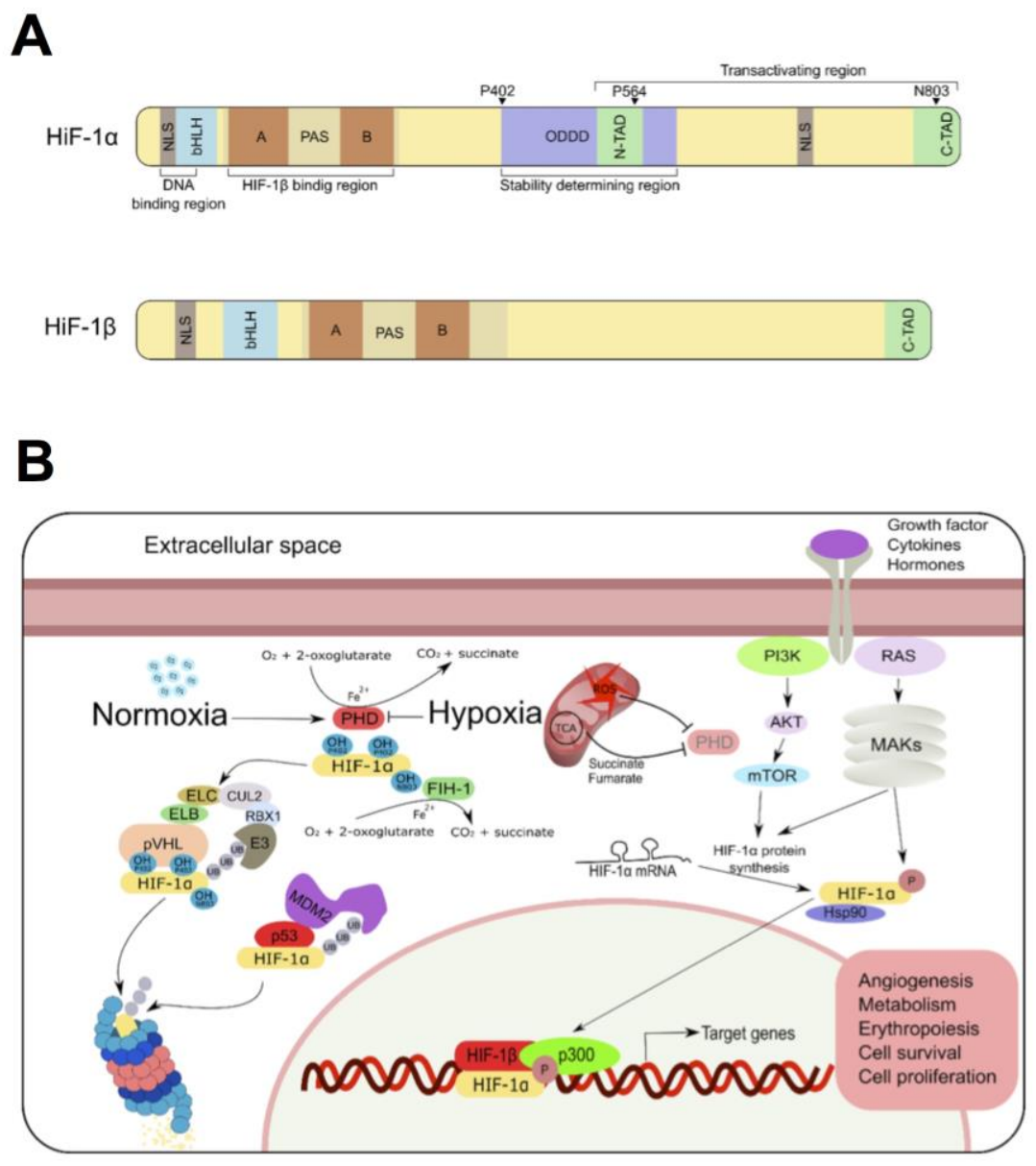

Figure 1. Structure and regulation of HIF-1 $\alpha$. (A) Schematic representation of human HIF-1 $\alpha$ and H1 $\beta$ structure. Both proteins form part to HLH-PAS transcription factor family and contain a N-terminal bHLH domain (implicated in DNA binding) and two PAS domains (responsible of its dimerization). HIF-1 $\alpha$ contains an oxygen-dependent degradation domain (ODDD) that mediates oxygen-regulated stability, and two transactivation domains (TAD), that mediate its transcriptional activity and its stability. (B) In normoxia, HIF-1 $\alpha$ is subjected to oxygen-dependent hydroxylation by PHD hydroxylases, conducting HIF- $1 \alpha$ to ubiquitination by the pVHL and proteasomal degradation. MDM2/p53 are also involved in ubiquitination and degradation of HIF1A protein in the VHL-independent manner. Under low oxygen levels (as well as some metabolites of TCA cycle) PHD is inhibited, HIF- $1 \alpha$ translocates to the nucleus and promotes the activation of target genes. Transactivation of HIF- $1 \alpha$ could be also induced by PI3K/MAPKs signaling pathways upon activation of some growth factor, hormones and cytokines.

The basic domain and the carboxy-terminus of PAS are specifically required for DNA binding of HIF-1 to the HRE DNA sequence 5V-RCGTG-3V, whereas the HLH domain and the amino-terminus of the two subunits of PAS proteins mediate their dimerization [6]. In addition to ubiquitous HIF- $1 \alpha$ and HIF- $1 \beta$, both subunits exist as a series of isoforms encoded by distinct genetic loci with different splice variants $[7,8,9,10]$. HIF- $1 \alpha$ constitutes the most prominent member of the three HIF-1 $\alpha$ subunits in the human genome. The most important structural elements of HIF- $1 \alpha$ are summarized in Figure 1A. HIF-1 has two nuclear location sequences (NLS) at the amino (residues 17-74) and carboxyl (residues 718-721) ends of the protein [11]. The stability of the protein is mainly regulated at the oxygen dependent degradation domain (ODDD). This domain contains two peptide sequences rich in proline (P), glutamic acid $(E)$, serine $(S)$, and threonine $(T)$ at 
residues 499-518 and 581-600 [3]. PEST-like motifs are present in short-lived proteins rapidly targeted for intracellular degradation. They mediate HIF-1 degradation by the ubiquitin-proteasome pathway [12, 13]. HIF-1 $\alpha$ also contains two transactivation domains, N-TAD (residues 531-575) and C-TAD (residues 786-826) [14]. Under hypoxia several co-activators such as CBP/p300/SRC-1 interact with the C-TAD inducing HIF-1 $\alpha$ transcriptional activity, while N-TAD is responsible for stabilizing HIF-1 $\alpha$ against degradation [15].

\subsection{Regulation of HIF-1 $\alpha$ expression, protein levels and transcriptional activity}

Although HIF-1 $\alpha$ is tightly regulated at the transcriptional, translational and posttranslational levels [4], protein degradation plays a dominant role in regulating its activity.

\subsubsection{Oxygen-dependent regulation}

Most of HIF-1 regulation is mediated by the HIF- $1 \alpha$ subunit. Under normoxic conditions, HIF-1 $\alpha$ protein is constitutively synthesized and rapidly targeted for ubiquitination and proteasomal degradation, thus keeping minimal steady-state levels. In this scenario, HIF-1 $\alpha$ becomes hydroxylated by members of the prolyl hydroxylase domain (PHD) family on two specific prolines (P402 and P564) of the ODDD and NTAD domains, respectively [16, 17, 18]. Hydroxylation of these proline residues generates a binding site for an E3-ubiquitin ligase complex that contains the von Hippel Lindau protein (pVHL), elongin B (ELB), elongin C (ELC), cullin 2 (CUL2), and ring box protein 1 (RBX1). As a result, HIF $\alpha$ is polyubiquitinated and degraded by the proteasome $[19,20,21$, 22] (Figure 1A).

In addition to this oxygen-dependent regulation of HIF- $1 \alpha$ stability, oxygen affects DNA binding and transcriptional activity as well. This effect is mediated by the factor inhibiting HIF-1 $\alpha$ (FIH-1), an asparagyl hydroxylase that catalyzes the hydroxylation of Q803 within the C-TAD domain of HIF-1 $\alpha$. Hydroxylation of Q803 leads to a steric clash that prevents the binding of the p300 and CBP coactivators to HIF-1 $\alpha$, abolishing their transactivation [23].

In hypoxia, impaired hydroxylation of HIF-1 $\alpha$ allows dimerization of the transcriptional complex and the subsequent expression of its target genes. The mitochondrial electron transport chain (MEC) consumes the vast majority of cellular oxygen and may play an important role in HIF-1 $\alpha$ regulation by determining the amount of oxygen available to PHD enzymes $[24,25,26]$. In this sense, pharmacological or genetic inhibition of mitochondrial respiration may prevent the accumulation of HIF-1 $\alpha$ in hypoxia [27, 28]. However, there are other ways in which mitochondria affect the stability of HIF-1 $\alpha$ (Figure 1B). Thus, in addition to requiring 2-oxoglutarate as a co-substrate, several metabolites of the tricarboxylic acic (TCA) cycle, especially succinate and fumarate, inhibit the HIF hydroxylases [26, 29, 30, 31]. In addition, reactive oxygen species produced by MEC in hypoxia also increase the stability of HIF-1 $\alpha \quad[27,32,33,34,35]$.

\subsubsection{Growth factor signaling pathways}

HIF1 is induced by numerous stimuli other than hypoxia, including growth factors, cytokines and hormones [36, 37, 38, 39, 40, 41]. These signals lead to the activation of mTOR (by PI3K/AKT) and the mitogen activated protein kinases (MAPK) (by the RAS/RAF/MEK/ERK kinases cascade) which can phosphorylate 4E-BP1 favoring cap-dependent translation of HIF- $1 \alpha$ mRNA [42, 43, 44]. MAPKs also play an important role in the regulation of the transactivation activity of HIF-1. Once activated, members of this family phosphorylate HIF1 $\alpha$, enhancing the binding of the coactivator p300/CBP [43, 45].

\subsubsection{The Mdm2 pathway}

A complex interplay exists between p53 and HIF-1 $\alpha$. On one hand, HIF-1 $\alpha$ binds to Mdm2 (the mouse's double minute 2 homologue), inhibiting Mdm2-dependent degradation of p53 [46]. On the other hand, p53 also mediates HIF- $1 \alpha$ activity. In this sense, at moderate expression levels, p53 competes with HIF-1 $\alpha$ for p300, consequently decreasing the transcriptional activity of HIF- $1 \alpha$. 
Moreover, high levels of p53 expression lead to HIF-1 $\alpha$ degradation [47]. This is due to binding of p53 to HIF- $1 \alpha$ that allows Mdm2-mediated ubiquitination of HIF- $1 \alpha$ and its proteasomal degradation [48] (Figure 1B).

\subsubsection{Heat shock protein 90 (Hsp90)}

$\mathrm{HIF} \alpha$ stability is also regulated by other signaling pathways, such as Hsp90 inhibitors that promote HIF $\alpha$ degradation in a pVHL-independent manner [49, 50]. In addition, Hsp90 is known to bind directly with HIF- $1 \alpha$ inducing some conformational changes in its structure to fit and couple with HIF-1 $\beta$ initiating its transactivation [51] (Figure 1b).

\subsection{HIF-1 $\alpha$ in cancer}

Cancer is defined as the autonomous growth and spread of a clone of somatic cells, under selective pressure, which is able to use multiple cellular pathways to modify its environment in favor of its own proliferation and against the needs of the organism, escaping physiological constraints on cell growth, including immune surveillance [52].

As the cell clone grows, its core becomes further removed from the blood supply and changes in oxygen availability are key for tumor cells to reorganize their metabolism in order to match oxygen supply with cellular demands. Thus, hypoxia becomes one of the key features of tumor microenvironment [53], a fact first reported in early studies where hypoxic cells were shown to surround the necrotic center in histological sections of lung carcinomas [54] and later demonstrated in essentially all solid tumors (reviewed in [53]). Intratumoral hypoxia is widespread and almost independent of tumor size, grade, stage, or histology [55]. Numerous studies have elucidated the molecular mechanisms involved in the cellular response to hypoxia, and three leaders in the field have been awarded recently the Nobel Prize in Medicine for their achievements, including their seminal work on HIF- $1 \alpha$, a critical transcription factor for adaptation to hypoxia [56, 57] (https://www.nobelprize.org/prizes/medicine/2019/summary/).

HIF- $1 \alpha$ regulates a number of physiological pathways involved in cancer, such as cell proliferation, survival, apoptosis, angiogenesis, glucose metabolism, immune cell activation and stem cell regulation $[56,58]$. In particular, HIF-1 $\alpha$ plays an important role in at least two of the main biological capabilities acquired during the multistep process of tumor development (the "hallmarks" of cancer, [52]): reprogramming cell metabolism and inducing angiogenesis.

\subsubsection{Role of HIF in reprogramming cancer cell metabolism}

When oxygen is available to mammalian cells, MEC and oxidative phosphorylation allow the highest yield of ATP from glucose, but many tumor cells choose oxygen-independent glycolysis even in normoxia conditions ("aerobic glycolysis" or Warburg effect) to extract smaller amounts of ATP but also valuable metabolites essential for the rapid growth of neoplasms [59]. Reaching this "sweet spot" of optimal utilization of glucose that maximizes cell growth requires a well-coordinated rearrangement of cell metabolism. Although HIF-1 $\alpha$ has long been recognized as a key player in response to hypoxia, hypoxia-independent mechanisms for HIF-1 $\alpha$ signaling have also been recently reported when oxygen is available to the cell ("pseudohypoxic" conditions) [60].

Reviewing the number of cancer types where HIF-1 $\alpha$ is part of the oncogenic process exceeds the aim of this article. In the recent Pancancer analysis of more than 2500 cancer genomes, VHL, a tumor suppressor gene (TSG) and the key regulator of HIF-1 $\alpha$, was among the most commonly mutated TSGs, following the highly prevalent TP53, CDKN2A/B, PTEN and SMAD4 [61]. Given its historical relevance, we will center this review on renal cancer, a type of malignancy that was central to the understanding of the role of hypoxia, angiogenesis and metabolism in cancer [62]. The study of hereditary cancer syndromes was, like in other examples of TSGs, crucial to the discovery of the mechanism of disease involving VHL. VHL (von Hippel-Lindau) family members carrying loss-of-function (LoF) mutations at the VHL gene are predisposed to kidney cancers. In particular, carriers display an autosomal dominant risk for clear cell-type renal cell carcinoma (ccRCC) in 
addition to other health problems [63]. Moreover, another type of RCC, named papillary-type 2 RCC, where VHL mutations are not involved, is known to harbor mutations in the gene for Fumarate Hydroxylase (FH), an enzyme of the TCA cycle. These mutations deregulate HIF expression also, underscoring the important role of angiogenic and metabolic responses in renal carcinoma.

LoF mutations at VHL are observed in a majority of ccRCC, interfering with HIF- $1 \alpha$ degradation and promoting a pseudohypoxic metabolic reprogramming of cancer cells. Stabilized HIF- $1 \alpha$ translocates to the nucleus, where it dimerizes with HIF $\beta$ and upregulates transcription of genes related to cellular metabolism, reprograming it towards aerobic glycolysis by increasing conversion from pyruvate to lactate (via upregulation of LDHA) and by blocking pyruvate conversion to acetyl-CoA by PDH (via upregulation of PDK1). Stable HIF also increases transcription of transporters for nutrients such as glucose and glutamine, ultimately enhancing the glycolytic and reductive carboxylation pathways, respectively [64]. In addition, HIF suppresses aerobic respiration by increasing levels of BCL2-related BNIP3 and BNIP3L, which leads to mitochondrial autophagy [65, 66]. HIF also interferes with aerobic respiration via microRNAs, such as miR-210, which disrupts Fe-S clusters necessary for the MCE [67]. Another important consequence of HIF stabilization in cancer is that, by upregulating the expression of glycolytic enzyme pyruvate kinase M2 (PKM2), it amplifies its own transcriptional activity, resulting in a positive-feedback mechanism [68].

\subsubsection{Role of HIF in cancer neoangiogenesis}

The capability to induce abnormal vascular growth that ensures abundant supply of nutrients is another important hallmark of cancer and it has been one of the most successful targets of modern cancer therapy [52]. Neoangiogenesis is particularly conspicuous in renal cell carcinoma and prominent vascular remodeling as been linked to HIF disregulation as a consequence of VHL mutations [69]. The key molecular event in tumor angiogenesis is the increase in Vascular Endothelial Growth Factor (VEGF)-A induced by the hypoxia resulting from tumor growth but also from mutations in the HIF pathway [70]. Many other factors are involved in blood vessel growth in tumors [71]. These complex angiogenesis patterns and disregulation of vessel stabilization and maturation have been also well documented in renal carcinoma [72].

\subsubsection{Association of HIF-1 $\alpha$ expression and cancer prognosis}

Although the complexities of cancer prognosis (the high variability of tumor mutations, histological types, grades and stages) makes it too simplistic to think that the levels of expression of a single gene such as HIF1 $A$ might have significant impact on prognosis, increased HIF- $1 \alpha$ and HIF- $2 \alpha$ protein levels in diagnostic tumor biopsies have been correlated with poor prognosis in other types of cancer also, such as brain, breast, colon, cervix, endometrium, head/neck, lung, ovary, pancreas, prostate, rectum and stomach (reviewed in [1]). More recently, high HIF-1 $\alpha$ expression has been studied in triple-negative breast cancer (TNBC) [73]. TNBC are a heterogeneous group of poorly differentiated, highly aggressive and metastatic breast cancer type. They lack specific molecular-targeted therapy and there is an urgent need to find effective biomarkers rather than relying of their lack of hormone receptors and Her2 expression to define this subgroup. These authors [73] found that HIF-1 $\alpha$ and c-Myc expression detected by immunohistochemistry could add to the development of a prognostic nomogram including histological grade and stage of cancer (based on tumor size $(\mathrm{T})$, lymph node involvement $(\mathrm{N})$ and distant metastases $(\mathrm{M})$, known as TNM status). In an effort to validate the proposed nomogram in our institution, we are currently evaluating the feasibility of including HIF-1 $\alpha$ immunohistochemistry in the biomarker profile (Figure 2). As a transcription factor induced in tumor cells by hypoxic environmental stress, HIF-1 $\alpha$ could regulate a variety of downstream genes, thereby increasing the invasive ability of tumors and their resistance against standard radiotherapy and chemotherapy. 


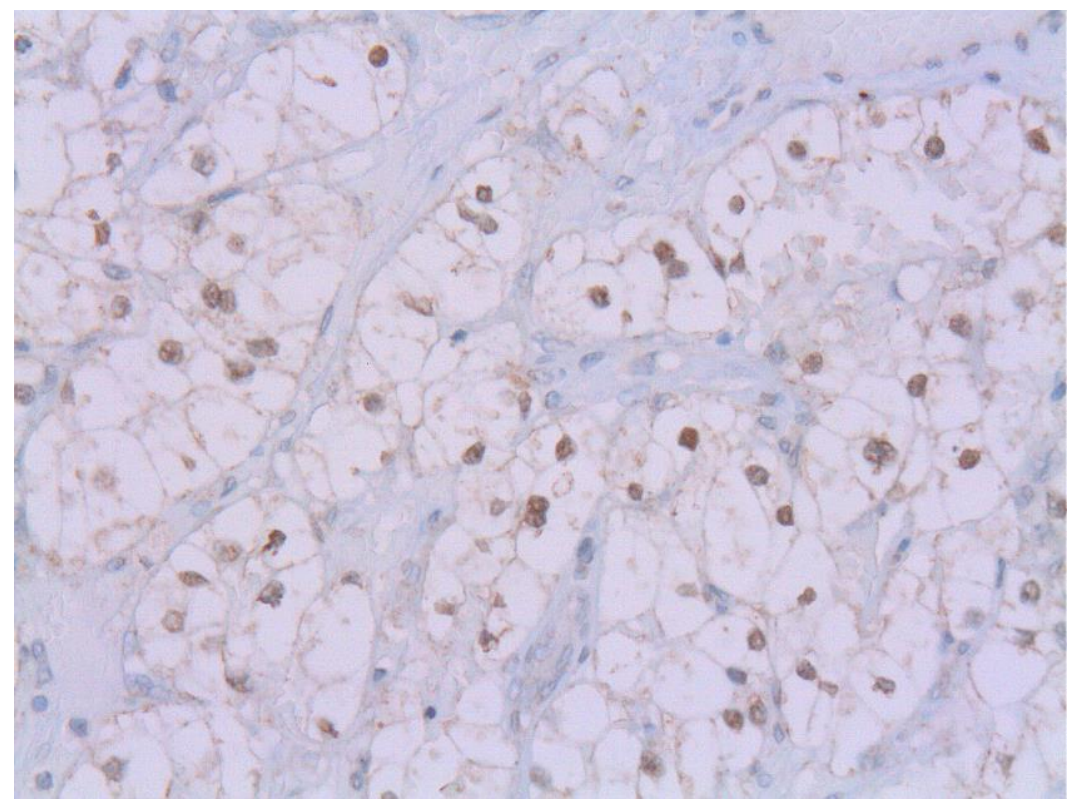

Figure 2. Nuclear HIF-1 $\alpha$ expression (brown staining) in clear cell renal carcinoma. Common deletions of the VHL gene result in lack of HIF1 degradation, with the subsequent activation of HIF1 as a nuclear transcription factor that drives tumor cell proliferation.

\section{NQO1 as a protein chaperone: current knowledge and potential application to target HIF-1 $\alpha$ stability}

The recent description of NQO1 as a protein chaperone protecting HIF-1 $\alpha$ against degradation [74] supports that targeting this protein-protein interaction (PPI) could allow inactivation of HIF-1 $\alpha$. Since our knowledge on this particular PPI is very limited, in this section we will describe a wealth of information available for the activity and stability of NQO1, focusing on what we know on other PPI by which NQO1 acts as a chaperones and how small ligands and missense mutations are capable of modulating these PPI.

\subsection{Overview of NQO1 expression, regulation and functions: on the potential roles of $\mathrm{O}_{2}$ levels and HIF-1 $\alpha$}

$\mathrm{NAD}(\mathrm{P}) \mathrm{H}$ quinone oxidoreductase 1 (NQO1; DT-diaphorase; EC 1.6.5.2) functions as a homodimer of $31 \mathrm{kDa}$ subunits [75, 76]. Each subunit contains two domains: an N-terminal domain (NTD, comprising approximately residues 1-225), that binds tightly one molecule of FAD and is capable of folding and assembly into dimers autonomously, and a C-terminal domain (CTD, comprising the last 40-50 residues) that completes the monomer:monomer interface and the binding sites of $\mathrm{NAD}(\mathrm{P}) \mathrm{H}$ and the substrates (Figure $3 \mathrm{~A})[75,77,78,79,80,81]$. Its main enzymatic function is to catalyse the two electron reduction of quinones, thus avoiding the production of reactive, and potentially cytotoxic, semiquinones (Table A1) [82]. Since one of its substrates is menadione (vitamin K3) it can function in blood clotting, although its role appears to be minor compared to vitamin $\mathrm{K}$ oxidoreductase [83]. Other substrates include $\alpha$-tocopherol-quinone and ubiquinone, which are maintained in their reduced (antioxidant) forms by the enzyme [84, 85]. NQO1 can also catalyse the reduction of superoxide radicals and thus plays a role in directly protecting the cell from reactive oxygen species [86]. The enzymatic cycle of NQO1 follows a ping-pong mechanism with two main steps or semireactions (Figure 3B): in a first one, $\mathrm{NAD}(\mathrm{P}) \mathrm{H}$ binds to the holo-form (NQO1 holo) of the enzyme (FAD is not released during the cycle), consequently reducing the flavin to $\mathrm{FADH}_{2}$ and releasing $\mathrm{NAD}(\mathrm{P})^{+}$. This reductive half-reaction is extremely fast, with a rate constant in the range of $10^{9} \mathrm{M}^{-1} \cdot \mathrm{s}^{-1}$. Importantly, the rate of this reductive half-reaction is strictly NADH-dependent, and thus, should be accelerated due to the HIF-mediated enhancement of aerobic glycolysis (raising cytosolic NADH levels, section 1.3.1); in a second and slower step (with a rate constant of $\left.10^{5}-10^{6} \mathrm{M}^{-1} \cdot \mathrm{s}^{-1}\right)$, the oxidative half-reaction, the substrate binds and is reduced by the 
$\mathrm{FADH}_{2}$, thus releasing the reduced substrate and regenerating the holo-enzyme [76, 79]. Dicoumarol, a potent anticoagulant and mitochondrial uncoupling agent, acts as a competitive inhibitor of $\mathrm{NAD}(\mathrm{P}) \mathrm{H}$ during the NQO1 cycle (Table A1) [87]. The high level of NQO1 expression in some cancer cells, coupled with its role in defence against ROS, has led to the suggestion that NQO1 inhibition may be a novel therapy for the disease. Dicoumarol is an effective inhibitor of pancreatic cancer cells in culture, but no NQO1 inhibitors are yet in clinical use [88].
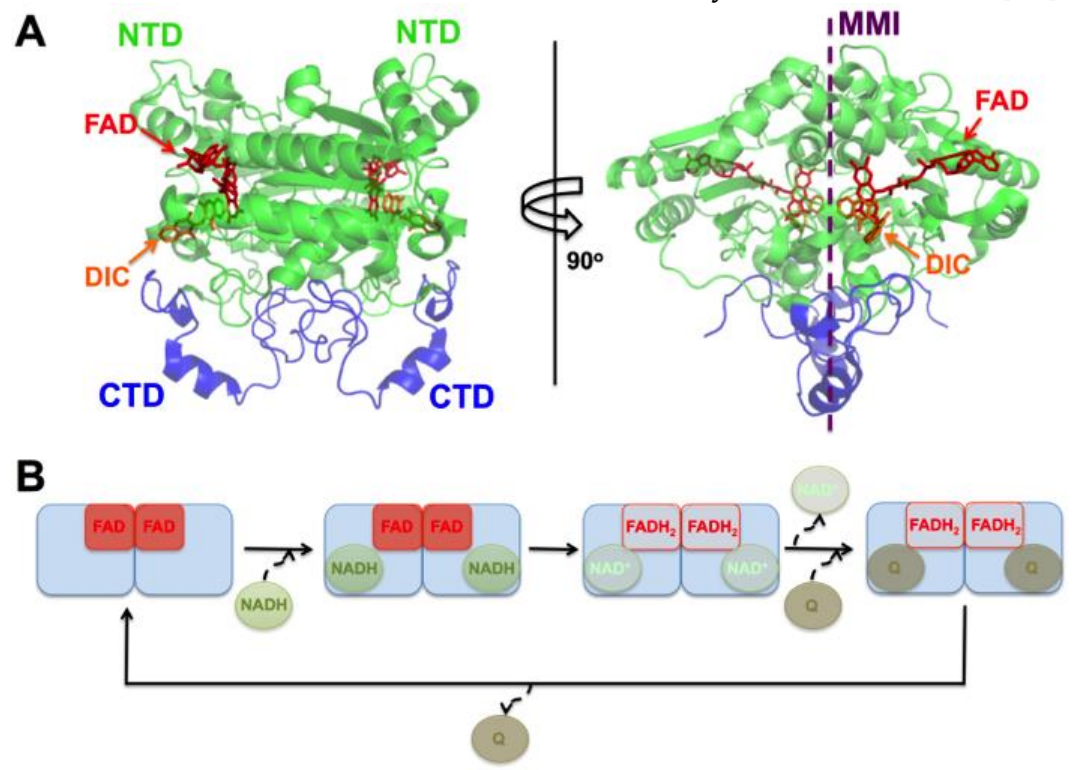

Figure 3. Structure and enzymatic cycle of NQO1. (A) Three-dimensional structure of NQO1dic (with FAD and dicoumarol bound)(PDB ID 2F1O). The N-terminal (NTD) and C-terminal (CTD) domains are indicated. MMI stands for the monomer:monomer interface. (B) Schematic representation of the catalytic cycle of NQO1.

The NQO1 protein has also non-enzymatic functions in which it mostly participates in PPI, mediating the stability of its binding partners (Figure 4 and Table A2). Indeed, and as we will further discuss in sections 2.2 and 2.3, several of the ligation states populated of NQO1 during the catalytic cycle (NQO1holo, either oxidized and reduced, or the dead-end complex of the holo-enzyme with dicoumarol, NQO1 dic) are very relevant to the discussion of PPIs developed by NQO1.

NQO1 is also known to undergo different post-translational modifications (PTMs), some of which have been characterized in a site-specific manner revealing that these modulate NQO1 function and stability in different manners. Phosphorylation of NQO1 at T128 by the kinase Akt results in polyubiquitination and degradation of NQO1 via the proteasome [89]. A phosphomimetic mutation on S82 showed reduced FAD binding affinity and consequent loss of intracellular protein stability, although the kinase involved in this phosphorylation event has not been identified yet [90]. Consequently, phosphorylation of NQO1 at different sites may have an impact on the intracellular stability of its protein partners through destabilization of NQO1.

NQO1 is expressed in most human cell types (https://www.genecards.org/cgi-bin/carddisp.pl?gene=NQO1) and its expression can be upregulated in response to stress. Two control elements are located upstream of the human NQO1 gene - the antioxidant response element (ARE) and the xenobiotic response element (XRE) [91, 92, 93, 94]. A key regulator of the ARE is nuclear factor erythroid 2-related factor 2 (Nrf2). This transcription factor from the basic leucine zipper family is located in the cytosol under non-stressed conditions. Here it interacts with Kelch like-ECH-associated protein 1 (KEAP1) that targets it for ubiquitin-mediated proteasomal degradation $[95,96]$. Oxidative stress is sensed by the oxidation of disulphide bonds in KEAP1 [97]. This releases Nrf2, which translocates to the nucleus and, together with members of the small musculoaponeurotic fibrosarcoma protein family (sMaF), binds to AREs [98]. This results in the recruitment of the Mediator complex, the acetylation of Nrf2 and the activation of a range of genes involved in antioxidant defense, including NQO1 [99, 100, 101]. 
Nrf2 also upregulates genes for NADPH generation, thus ensuring that enzymes like NQO1 have sufficient reduced cofactor $[102,103]$. The ARE also responds to some antioxidants (e.g. resveratrol and quercetin), by upregulating the expression of NQO1 and other antioxidant enzymes [104, 105]. Interestingly, the ARE that controls the expression of NQO1, is also activated by hypoxic conditions [106]. Thus, NQO1 protein levels increase under hypoxic conditions [107]. Consequently, NQO1 is overexpressed in tumours due to their hypoxic environment.
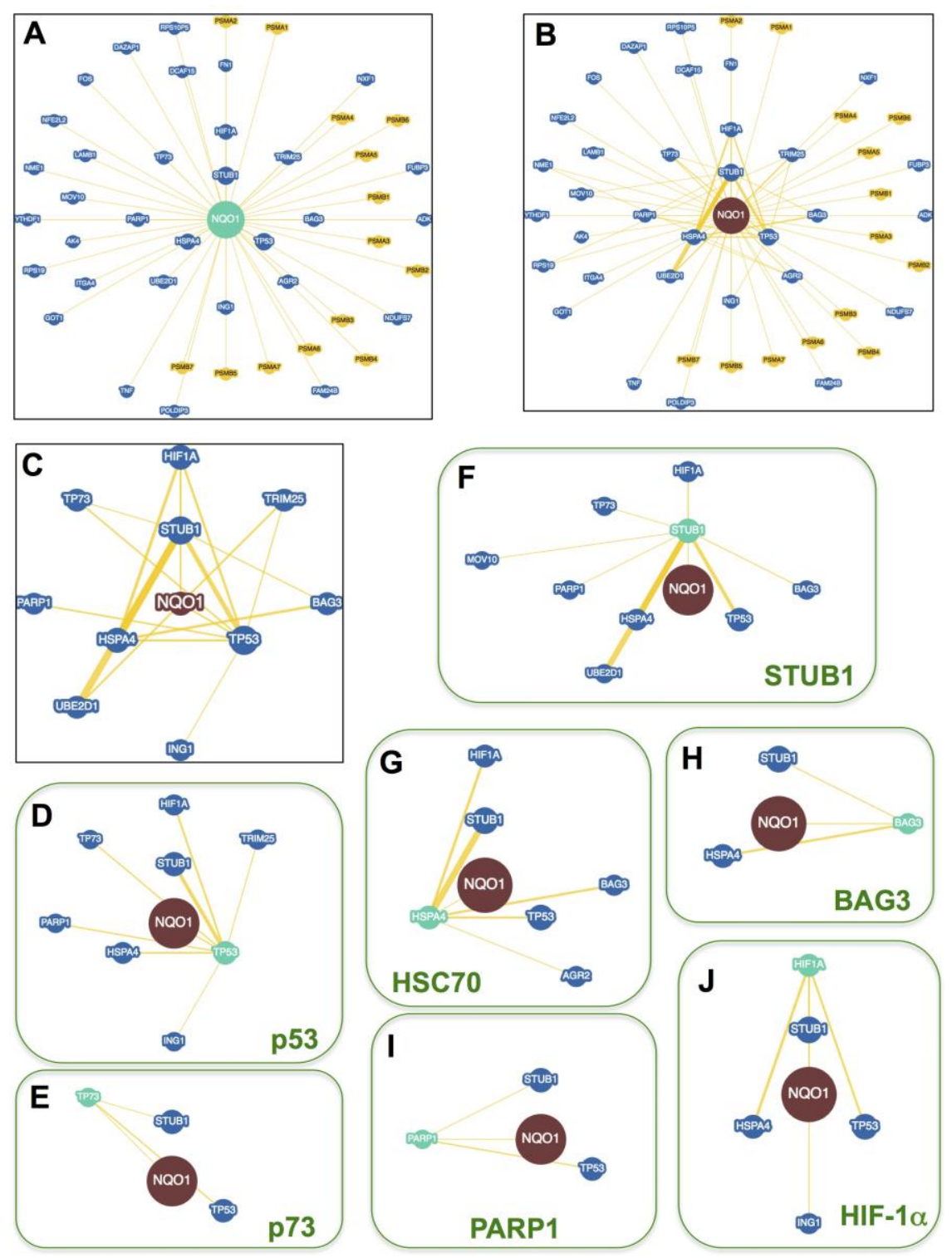

Figure 4. The NQO1 interactome. (A) NQO1 protein partners described in at least one report. (B) Connectivity between NQO1 partners. The shorter the radial distance between a partner and NQO1 indicates a higher interconnectivity. Partners in yellow are from mouse and in blue from human. (C) A zoom from panel B shows the most highly interconnected partners of NQO1. (F-J) Interactions between NQO1 partners in panel C and other proteins to highlight their different interconnectivity. The thickness of connecting yellow lines is related to the number of reports describing the interaction. Data were retrieved from the BioGRID database (https://thebiogrid.org/108072) [108].

The XRE is activated by the aryl hydrocarbon receptor (AhR), a basic helix-loop-helix transcription factor. The protein binds to a wide range of hydrophobic xenobiotics and translocates to the nucleus in response. Here it heterodimerises with aryl hydrocarbon nuclear translocator (ARNT or HIF1 $\beta$ ) and binds the XRE $[109,110]$. In the case of the NQO1 gene, AhR at the XRE and Nrf2 functionally cooperate to regulate its expression [111]. Like the ARE, the XRE can be induced 
by hypoxia [112]. Although HIF-1 $\alpha$ also partners with HIF1 $\beta$ to regulate transcription, siRNA silencing of the HIF1 $\alpha$ gene does not affect NQO1 expression [113]. This suggests that HIF1 $\alpha$ is not directly involved in regulating NQO1 expression.

\subsection{NQO1 macromolecular interactions}

To date, there are 47 protein partners of NQO1 compiled in the BioGRID database (https://thebiogrid.org/108072) [108]. This set includes 33 human proteins (actually one is a pseudo-gene product). The remaining 14 are from rodents and belong to different subunits of the $20 \mathrm{~S}$ proteasome (Figure 4A). In addition, NQO1 can interact specifically with certain RNAs modulating their expression [114]. Focusing on protein partners, there is certain evidence within the NQO1 interactome supporting that different partners (i.e. nodes) of this network can interact not only with NQO1 but also among each other, Consequently, this could generate regulatory circuits upon interaction of different partners in two- or multiple-way manners (i.e. binary, ternary, quaternary....complexes; Figure 4B). This also suggests that we may affect the properties (e.g. intracellular activity or stability) of one node by targeting different adjacent nodes in the network, an effect that could be amplified particularly in nodes with high connectivity. The most representative and consistently reported nodes with such a high connectivity for NQO1 are shown in Figure 4C and Table A2. Importantly, HIF-1 $\alpha$ belongs to this group.

A critical reason for better understanding the interactome of NQO1 emerges from a well-known consequence on its interaction with partners: it leads to changes in the stability of the partner against (Ub-dependent or -independent) proteasomal degradation. Thus effects on the intracellular levels of NQO1 or in the strength of its interaction with partners may translate into altered stability of the nodes in the interactomic network. For instance, reducing the availability of the FAD precursor riboflavin leads to increased population of the flavin-free NQO1apo state, which is very sensitive to proteasomal degradation through ubiquitin-dependent and -independent mechanisms [115, 116]. This is in part caused by the destabilization of the CTD of NQO1 in the absence of bound FAD that promotes its ubiquitination and degradation [116]. Remarkably, addition of the inhibitor dicoumarol does not stabilize the NQO1 protein intracellularly but seems to reduce its ability to interact with and stabilize these protein partners (see Table A2). Binding of $\mathrm{NAD}(\mathrm{P}) \mathrm{H}$, which reduces the bound flavin cofactor, seems to enhance the interaction of NQO1 with these protein partners ( [117], Table A2). A recent study also suggested that NQO1 with a reduced flavin cofactor could be a physiologically important state in the cell [118], and thus very relevant to understand the interactome dynamics of NQO1 (note that the population of this state can be promoted due to HIF-mediated increased levels of cytosolic NADH, section 1.3.1). Additional factors modulating NQO1 intracellular stability, such as protein phosphorylation events, small ion binding or single amino acid changes $[119,120,121,122,123]$, may thus propagate and amplify these effects to the stability of the NQO1 protein partners. 
A

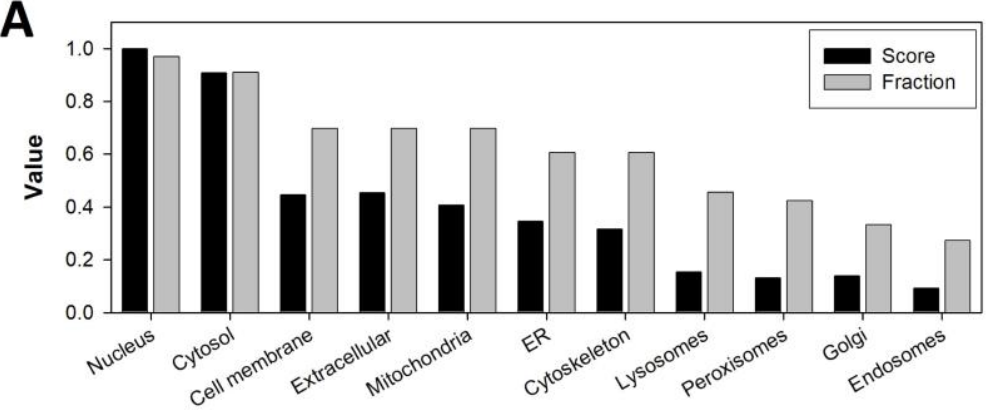

B

Subcellular location

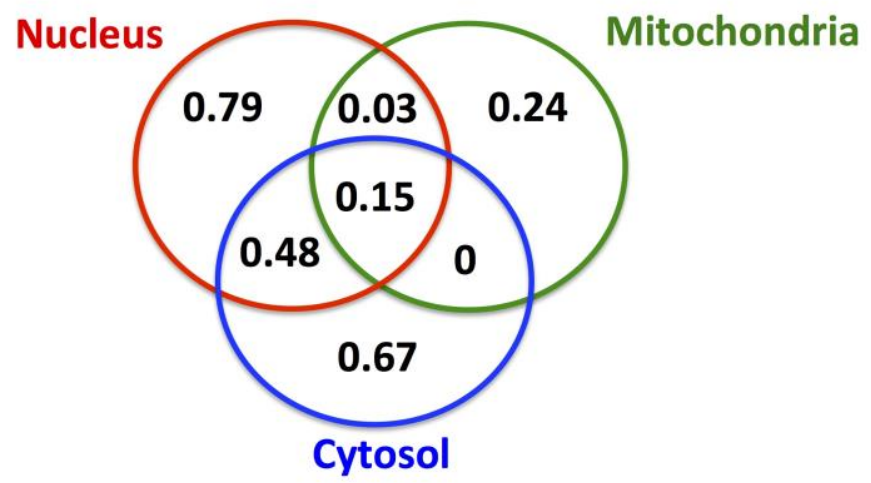

Figure 5. Subcellular location of NQO1 interacting human partners based on data from GeneCards®. For all the interactors, the subcellular compartment (location) and its confidence (1-5, from the lowest to the highest) were retrieved from GeneCards ${ }^{\circledR}$. (A) Accumulated score for each organelle as the sum of the numerical degree of confidence for all partners found in a given compartment. The highest accumulated score (i.e. for the nucleus) was used to normalize yielding the Score. As Fraction, we refer to the fraction of all the partners found in a given organelle. Note that the ratio Score:Fraction gives a measure of the degree of confidence for finding a given partner in a given subcellular location. (B) Subcellular location of NQO1 partners in the three subcellular locations of NQO1 reported with confidence (i.e. equal or higher than 3) as the fraction of the total of NQO1 partners. Overlapping regions in the Venn diagram reveal the presence of an NQO1 partner in at least two subcellular locations.

Another critical issue for understanding the interaction of NQO1 with its partners and subsequent effects of these interactions on the stability of its interactome is the subcellular location of NQO1 and its partners. It is generally accepted that NQO1 subcellular location is primarily cytosolic, where it can fulfill its roles as antioxidant/detoxifiying enzyme and is able to interact with protein and RNA partners. However, there is also certain evidence supporting its location in other subcellular compartments, mostly mitochondria and the nucleus (with low confidence in other organelles)(Figure $5 \mathrm{~A}$;

GeneCards®; https://www.genecards.org/cgi-bin/carddisp.pl?gene=NQO1\&keywords=NQO1). Importantly, most of the protein partners of NQO1 also seem to primarily localize in the nucleus and the cytosol, and to a moderate extent in the mitochondria, cell membrane and extracellularly, apparently coexisting between more than one subcellular location (Figure 5A-B). In the case of the cytosol and the nucleus, about $50 \%$ of NQO1 partners may operate in any of these locations and translocate between these two to fulfill their roles in cytosolic and nuclear processes such as control of DNA expression (p53, HIF-1 $\alpha$ c-FOS, NRF-2, NME1, FUBP3), regulation of RNA and translation (POLDIP3, YTHDF1, NXF1, MOV10, DAZAP1, RPS19), regulation of nuclear protein function (PARP1 and TRIM25), protein folding and degradation (BAG-3, eIF4G1, DCAF15, HSPA4, STUB1, UBE2D1). In addition, a number of metabolic enzymes in the cytosol and mitochondria (ODC, NDUSF7, NME1, ADK, GOT1, AK4) could also interact with NQO1 in these compartments. Indeed, NQO1 
overexpression in mice is known to enhance glycolytic and mitochondrial respiration activities and enhance metabolic flexibility, mimicking the beneficial effects of caloric restriction [124]. It is worth noting that the proteasomal protein degradation machinery may operate through rather similar mechanisms in the cytosol and the nucleus $[125,126]$, and thus, the well-known chaperone role of NQO1 for different protein partners (see Table A2), may indeed operate in the cytosol thus increasing the levels of cytosolic proteins amenable to import to other organelles (such as nucleus or mitochondria; [74, 127]) and plausibly by stabilizing these proteins upon import of both the partner and NQO1 in these organelles. Noteworthy, although more rarely described, the presence of NQO1 in other subcellular locations such as cytoskeleton may explain other roles of the multifunctional NQO1 protein. For instance, recent studies have supported that NQO1 may provide an adequate supply of $\mathrm{NAD}^{+}$for deacetylase activity of different sirtuins associated with microtubule dynamics [118, 124, 128]. These studies also highlight the potential plasticity of NQO1 subcellular location during different cellular conditions or stages (e.g. the recruitment of cytosolic NQO1 to cytoskeletal structures during cell division [118]).

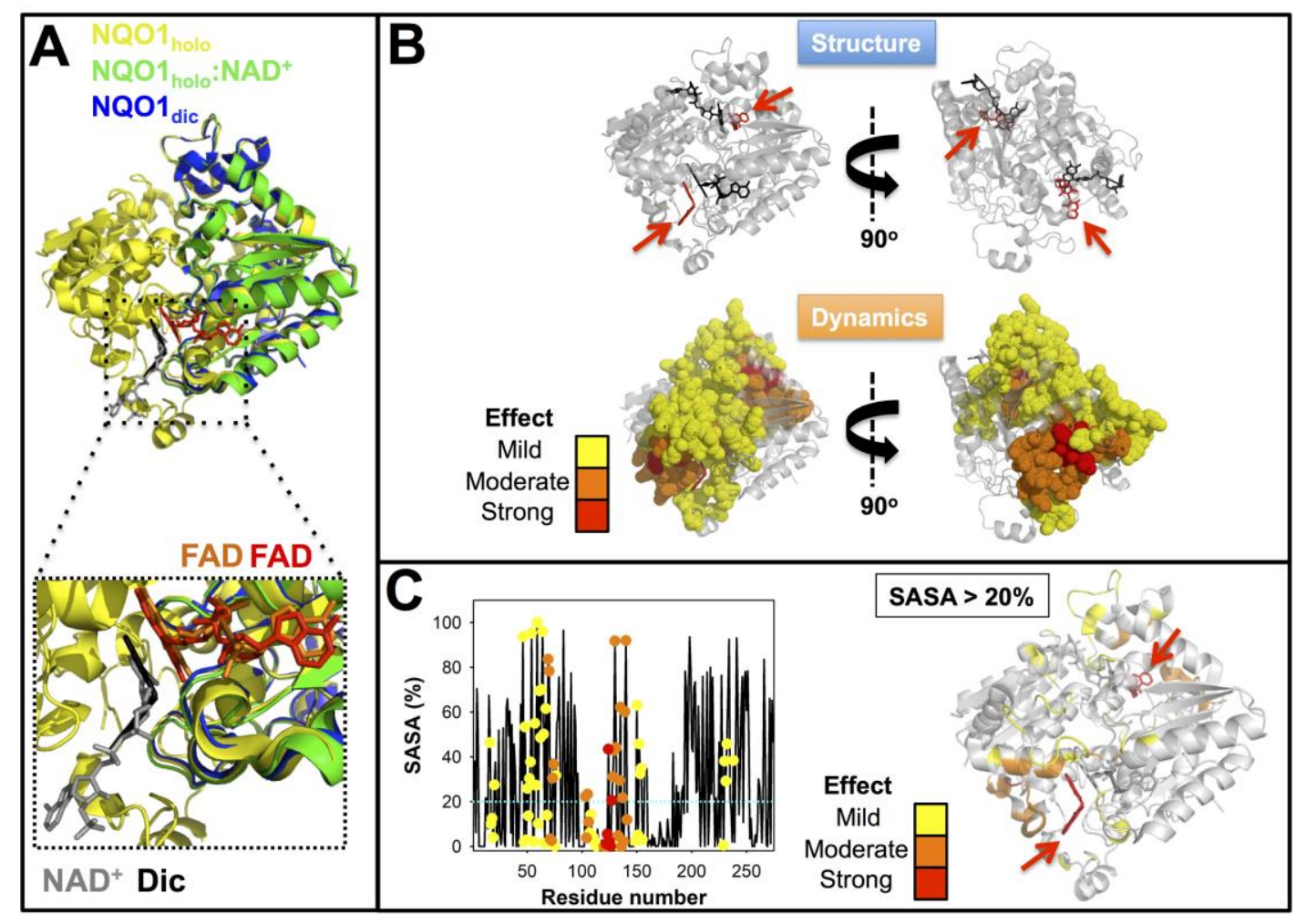

Figure 6. Structure and dynamics of NQO1 upon binding different ligands. (A) Structural overlay of the X-ray structures of NQO1 holo (1D4A), NQO1 holo:NAD ${ }^{+}$(kindly supplied by Profs. Mario Bianchet and Mario Amzel, John Hopkins University Medical School, Baltimore, USA) and NQO1dic (2F1O). The lower panel shows a zoom highlighting the position of the FAD (orange, NQO1 dic and red, NQO1 holo:NAD ${ }^{+}$, $\mathrm{NAD}^{+}$and dicoumarol (Dic). (B) Dicoumarol binding causes long-range effects on the structural dynamics of NQO1 WT. Residues shown in dot representation are those for which the structural dynamics is reduced according to HDXMS [129]. (C) Most of the residues whose dynamics is reduced upon dicoumarol binding are solvent-exposed. The plot in the right shows the solvent accessible surface area (SASA) for the each residue as calculated in [129] and colour circles indicate the magnitude of the change in structural dynamics. The figure on the left shows the structural location of solvent-exposed residues (SASA $>20 \%$ ). The color scales in panels B and C reflect the magnitude of the changes in protein dynamics according to [129] and red arrows indicate the position of dicoumarol. 
2.3. Changes in NQO1 stability, structure and dynamics upon ligand binding: implications for the stability of its protein partners

The functional chemistry of NQO1 is remarkably complex. At least four different ligation states (with small molecules bound) are relevant to understand the intracellular stability and enzymatic activity of NQO1 as well as its effects on the function and stability of its macromolecular partners: i) NQO1 apo, which has no ligand bound; ii) NQO1 holo, which contains a molecule of oxidized FAD per NQO1 monomer; iii) NQO1 holo-red, containing the FAD cofactor reduced upon interaction with $\mathrm{NAD}(\mathrm{P}) \mathrm{H}$ and hydride transfer; and iv) NQO1 dic, a ternary complex of NQO1 holo with the inhibitor dicoumarol bound. These different ligation states interact differently with NQO1 protein partners $[78,117,127]$. High-resolution structural models for these complexes are, to the best of our knowledge, not reported. Thus, we will focus in this section on the structural and dynamic consequences of ligand binding to NQO1 in an attempt to obtain some insight into their regulatory effects on NQO1 interactions with protein partners (always from an NQO1 point of view).

NQO1apo exists as a stable and expanded dimer characterized by significantly large conformational flexibility [76, 78, 79, 80, 119, 130, 131, 132]. Although no high resolution structural model is available for this state, recent kinetic studies using hydrogen-deuterium exchange mass spectrometry (HDXMS) have identified a minimal stable core that holds the protein dimer while most of the protein exists forming a highly dynamic structural ensemble, including the FAD and substrate binding sites in non-competent states for binding [129]. This remarkable conformational flexibility makes NQO1apo likely the most relevant state to understand the intracellular stability of NQO1, since the flexible CTD acts as initiation site for rapid degradation through ubiquitin-dependent and -independent proteasomal pathways [90, 116]. It is plausible that this unstable and highly dynamic NQO1apo state is not capable of interacting with NQO1 protein partners, or at least, does so with lower affinity [78].

Binding of FAD triggers a large conformational change leading to compaction of the protein dimer, increase in ordered secondary structure, overall conformational stabilization and a large decrease of protein dynamics that is sensed in almost the entire protein structure $[78,79,80,119$, $129,130,131,133]$. This NQO1 holo state is amenable for high-resolution structural studies [81](Figure 6A). This state is also known to be intracellularly stable and likely to interact with protein partners quite efficiently $[115,116,117,119,123]$.

Binding of $\mathrm{NAD}(\mathrm{P}) \mathrm{H}$ results in FAD reduction, leading to a state we named NQO1 holo-red. This reaction is extraordinarily fast (close to the diffusion limit) and this state is likely unstable unless strongly reducing and/or anaerobic conditions are used (at least in vitro, [79]). Consequently, detailed structural analyses on this state are non-existant. However, it is worth commenting on some studies carried out under less stringent (i.e. aerobic) conditions, particularly because a wealth of work support that generally, this state may strongly interact with NQO1 protein partners $[117,127]$. Using biochemical in vitro assays with $\operatorname{NADP}(\mathrm{H})$, it has been reported that NQO1 holo-red influences the conformation of the CTD affecting the interaction with antibodies raised against it [118] and apparently increasing the thermodynamic stability of this domain [80, 118]. Intriguingly, the changes in conformation and stability of the CTD reported for NQO1dic and NQO1 holo-red are strikingly similar, suggesting again that subtle differences in structure and dynamics between these two states are likely responsible for their opposing effects on the interaction of NQO1 with protein partners.

Binding of dicoumarol (or $\mathrm{NAD}^{+}$) causes small structural rearrangements in the protein structure $[75,78,81,131,134]$ (Figure 6A). Therefore, from NQO1 structural point of view, it is not straightforward to understand how NQO1dic prevents binding to or largely decrease binding affinity for macromolecular partners with subsequent effects on the stability of these partners [78, 127]. An alternative explanation has emerged from studies on NQO1 protein dynamics by HDXMS [129]. Binding of dicoumarol to WT NQO1 causes strong effects on NQO1 protein dynamics, affecting the local stability of the protein core and these effects propagate through long distances in the protein structure (Figure 6B). Some of these effects are sensed by the CTD (Figure 6B), which may explain how dicoumarol binding mildly increases the thermodynamic stability of this domain by about 1.5 
$\mathrm{kJ} \cdot \mathrm{mol}^{-1}[80,135]$. Interestingly, a significant fraction of the residues whose stabilities are affected by dicoumarol binding appear on the protein surface and far from the ligand binding site (Figure 6C). This may imply that NQO1 dic interacts differently with macromolecular partners through changes in the local stability and dynamics of the(se) binding site(s), which are likely located on NQO1 protein surface.

\subsection{Mutations and polymorphisms in NQO1. Disease and protein interactions}

The association of NQO1 activity with several human diseases with a huge social impact, particularly cancer, HIV infection and neurological and cardiovascular diseases, has attracted the attention towards the effects of naturally-occurring single amino acid changes on NQO1 and the predisposition provided by these changes towards disease $[76,79,116,119,122,123,130,133,136$, $137,138,139,140,141]$. There are 106 missense variants described in human population (ExAC and gnomAD

databases;

https://gnomad.broadinstitute.org/gene/ENSG00000181019?dataset=gnomad r2 1) and 47 missense variants in the COSMIC database (https://cancer.sanger.ac.uk/cosmic/gene/analysis?ln=NQO1\#variants). By far, the two most common single amino acid variants are p.P187S and p.R139W, with allelic frequencies in human population of about 0.25 and 0.03 , respectively. Consequently, these two polymorphisms have been characterized in some detail. In addition, and to the best of our knowledge, only one other naturally-occurring single amino acid variant, p.K240Q (found in gnomAD and COSMIC databases), has been characterized. Since the studies aimed at characterizing the effects of these single amino acid variants have been recently reviewed [76, 132], we will just outline in this section some of the key features described for them focusing on their potential impact on the interaction with protein partners and with those ligands known to modulate NQO1:protein interactions.

The intracellular effects of p.P187S can be ascribed to changes in its stability and activity, respectively. This variant decreases by 10- to 40-fold the affinity for FAD thus promoting the population of NQO1 apo [79, 120, 122, 133, 136, 142]. Unlike WT NQO1, p.P187S in both NQO1 holo and NQO1apo are degraded similarly, due to a strong thermodynamic destabilization of the CTD in NQO1 holo that triggers ubiquitination and degradation $[78,79,116,119,120,122]$. Remarkably, the crystal structure of p.P187S in the NQO1 dic state is virtually identical to that of the WT enzyme [79]. This seems to be paradoxical, because P187 is fully buried in the protein structure, close to the NQO1 dimer interface and belongs to the minimally stable core of NQO1 apo, and thus, a mutation to serine should have catastrophic effects on protein structure and function $[129,136]$. Detailed biochemical, biophysical, computational and mutational studies have shown that the effects of p.P187S are pleiotropic in the structure, function and stability of $\mathrm{NQO}_{\text {apo }}$ and NQO1 holo, highlighting the critical role of propagation of the local stability effects due to p.P187S to long distances in the protein structure and affecting the dynamics and stability of critical regions of NQO1 function $[78,79,90$, $119,120,122,131,133,136,137]$. These studies on p.P187S have also supported that different functional sites located far (over 10-20 $\mathrm{A}$ ) in the structure are functionally and energetically coupled, and thus, we might modify the interaction of NQO1 with its partners by using an allosteric site (i.e. a ligand binding or mutated site) far from the protein:protein binding site. p.P187S is known to affect the interaction with NQO1 partners and lead to their destabilization, although it is not clear whether the origin of these alteration resides mainly in altered protein:protein interactions (i.e. binding affinity) or in the decreased intracellular stability of this variant that is reflected in those of the partners $[78,115,116,119,120,123,143]$.

The polymorphism p.R139W represents a beautiful example in which a single nucleotide change may affect protein functionality at post-transcriptional and translational levels. In the one hand, it affects normal processing of NQO1 mRNA leading to exon 4 skipping, that produces a shorter version of the NQO1 protein that is extremely unstable inside cells due to the lack of part of the catalytic site (residues 102-139) critical for protein folding and stability [144]. On the other hand, full-length NQO1 is also translated containing the single amino acid exchange p.R139W, which has only small effects on protein stability and function $[119,130,133]$. Consequently, the former effect is 
likely the prevalent one to explain the loss of intracellular NQO1 activity due to this polymorphism [119, 130, 133, 144]. In addition, it must be expected that the decrease in full-length NQO1 protein caused by this polymorphism may negatively impact the stability of protein partners, although to our knowledge, no experimental evidence for this is available.

The rare mutation p.K240Q was investigated to determine whether variable structural perturbations (mutations to glutamine as well as more perturbating variants such as changes to glycine and glutamate) in the CTD could propagate through the NQO1 structure to affect different functional sites [122, 136]. K240 is a solvent-exposed residue involved in a highly-stabilizing electrostatic network in the CTD [122]. This site accepted different types of mutations without compromising protein levels, activity, stability and solubility upon expression in E. coli. [122, 136]. However, detailed biophysical and biochemical experimentation, actually revealed that the p.K240Q mutation affected locally the stability of the CTD, and this effect was more pronounced in the more perturbing in the mutations p.K240G and p.K240E [122, 136]. A similar gradual effect was observed on the affinity for FAD, a remarkable result considering that the FAD binding site is located at $20 \AA$ from the altered site $[122,136]$. Studies with this mutation thus highlighted the plasticity of the NQO1 protein in different ligation states to transmit the effects of single amino acid changes and ligand binding. Due to this plasticity, we may anticipate that rare mutations found in cancer cell lines (COSMIC) or whole-genome sequence studies (gnomAD) such as p.K240Q would have certain effects on NQO1:protein interactions and consequently the stability of its partners. This hypothesis awaits to be tested experimentally.

\section{Targeting the chaperone role of NQO1 to inactivate HIF-1 $\alpha$ : future perspectives}

The chaperone role of NQO1 on HIF-1 $\alpha$ has been recently addressed in some detail in relation with hypoxia and normoxia [74]. While hypoxic and normoxic conditions provided somewhat different effects, the overall consequence of NQO1:HIF-1 $\alpha$ interaction was the stabilization of HIF-1 $\alpha$ upon interaction. The expression levels of NQO1 consistently modulated the levels of HIF-1 $\alpha$ likely due to the specific interaction of NQO1 with the ODD domain HIF-1 $\alpha$ in the cytosol, rather than to changes in HIF-1 $\alpha$ mRNA at the transcriptional level [74]. This interaction enhances the intracellular stability of HIF- $1 \alpha$ by suppressing its ubiquitination in the cytosol, and thus promoting its nuclear import and transcriptional activity [74]. This chaperone effect is enhanced under hypoxic conditions due to increased expression of NQO1 [74, 107]. Intriguingly, the presence of the p.P187S polymorphism did not prevent the chaperone action of NQO1, although it is well known to reduce NQO1 protein levels due to intracellular destabilization (see Section 2.4).

We could envision different strategies to disrupt NQO1 interaction with HIF-1 $\alpha$ leading to increased degradation of the latter:

i) To prevent PPI by targeting the PP binding site or an allosteric site. We must note that allosterism is likely a critical feature for the multifunctionality of both NQO1 (sections 2.3 and 2.4) and HIF-1 $\alpha[145,146]$. Allosterism in HIF- $1 \alpha$ is dramatically exemplified by the negative effector CITED2, that competes with HIF-1 $\alpha$ for the same binding site on CBP/p300 attenuating the transcriptional activity of HIF-1 $\alpha$ [145, 146]. Remarkably, CITED2 and HIF-1 $\alpha$ show the same binding affinity for $\mathrm{CBP} / \mathrm{p} 300$, although the former is much more efficient in displacing the latter from binary complexes with $\mathrm{CBP} / \mathrm{p} 300$ due to enhanced HIF- $1 \alpha$ release linked to the intrinsic disorder of the C-TAD domain. We must note that an important caveat to rational screening for ligands is the lack of high-resolution structural models neither for a complex of NQO1 with a partner nor for the ODD of HIF-1 $\alpha$. There is also no detailed biochemical mapping of the interaction site or plausible molecular models. In addition to identifying non-covalent binders, potential, specific covalent modifiers should also be considered ( $c f$ the cysteine modification of Giardia lamblia triose phosphate isomerase by omeprazole which destablises the dimer [147]).

ii) A high-throughput screen for ligands that target the formation of the NQO1: HIF-1 $\alpha$ complex. Both (i) and (ii) would require a rapid, reproducible, robust assay for the interaction in vitro, for example labeling of the proteins with a fluorophore and a quencher. A cell-based assay would also 
be required to test hits from the screen under in vivo conditions, for example proteins labeled with FRET donors and acceptors, co-immunoprecipitation or indirectly by measuring amounts of HIF1 $\alpha$. Although challenging due to several highly disordered regions in the HIF-1 $\alpha$ protein, such screening would be still feasible as recently reported for inhibiting PPI in the cancer-associated and intrinsically disordered protein NUPR1 $[148,149]$.

iii) To use dicoumarol-like molecules that may target that interaction with lower second-site effects [150, 151, 152]. It must be noted regarding this approach that the effect of NADH or dicoumarol have not been tested for the interaction of NQO1 with HIF- $1 \alpha$. Many dicoumarol analogues that function as NQO1 inhibitors have been reported. It is reasonable to assume that they would also antagonize the protein's interactions with binding partners in a similar way to dicoumarol. As such, they represent immediately available compounds, which could be tested for their ability to antagonize the NQO1/HIF1 $\alpha$ interaction. However they are likely to inhibit or antagonize many of NQO1's functions and may, therefore, cause significant off-target effects. Some of these may be undesirable in the context of cancer therapy, e.g. the antagonism of the NQO1/p53 interaction and consequent down-regulation of p53-mediated apoptosis [153, 154].

Author Contributions: I. B. F., E.S., D.J.T., R.P-M and A.L.P., writing-original draft, writing-review and editing.

Funding: This research was funded by the ERDF/Spanish Ministry of Science, Innovation and Universities-State Research Agency (Grant RTI2018-096246-B-I00, to A.L.P. and and SAF2015-69796 to E.S.), Consejería de Economía, Conocimiento, Empresas y Universidad, Junta de Andalucía (Grant P18-RT-2413, to A.L.P.).

Conflicts of Interest: The authors declare no conflict of interest. 


\section{Appendix A}

Tables A1 and A2 compile information on known NQO1 substrates, inhibitors and protein partners.

\begin{tabular}{|c|c|c|}
\hline \multicolumn{3}{|c|}{$\begin{array}{l}\text { Appendix A } \\
\text { Tables A1 and A2 compile information on known NQO1 substrates, inhibitors and protein partners. }\end{array}$} \\
\hline Compound & Comments & References \\
\hline \multicolumn{3}{|l|}{ Substrates } \\
\hline Dichlorophenolindolphenol (DCPIP) & Non-physiological, but often used in in vitro assays & {$[155,156]$} \\
\hline Menadione (Vitamin K3) & Reaction occurs in vivo but enzyme likely to play only a minor role in blood clotting & {$[83,156]$} \\
\hline Coenzyme $Q_{10}$ (ubiquinone) & NQO1 maintains this, and related compounds, in the reduced form & {$[157,158]$} \\
\hline Superoxide ions & Likely physiological role in directly combatting oxidative stress in vivo. & [86] \\
\hline $\mathrm{Fe}(I I I)$ ions & Probably non-physiological & [159] \\
\hline Idebenone & Important in the metabolism of this drug (a coenzyme $Q_{10}$ mimic) & [160] \\
\hline $\begin{array}{l}\text { (3-hydroxymethyl-5-aziridinyl-1-methyl-2-(H-indole-4, 7-indione)-propenol) } \\
\text { EO9 }\end{array}$ & Reduction activates this anticancer compound & [161] \\
\hline Quinone epoxides & Potentially important if members of this group of compounds used as drugs. & [162] \\
\hline$\beta$-lapachone & $\begin{array}{c}\text { Futile cycling involving NQO1 results in reduced cellular concentrations of } N A D(P) H \text { contributing to } \\
\text { cell death }\end{array}$ & {$[163,164]$} \\
\hline Mitomycin C & Reduction activates this akylating cytotoxic drug & {$[165,166]$} \\
\hline
\end{tabular}


17 of 29

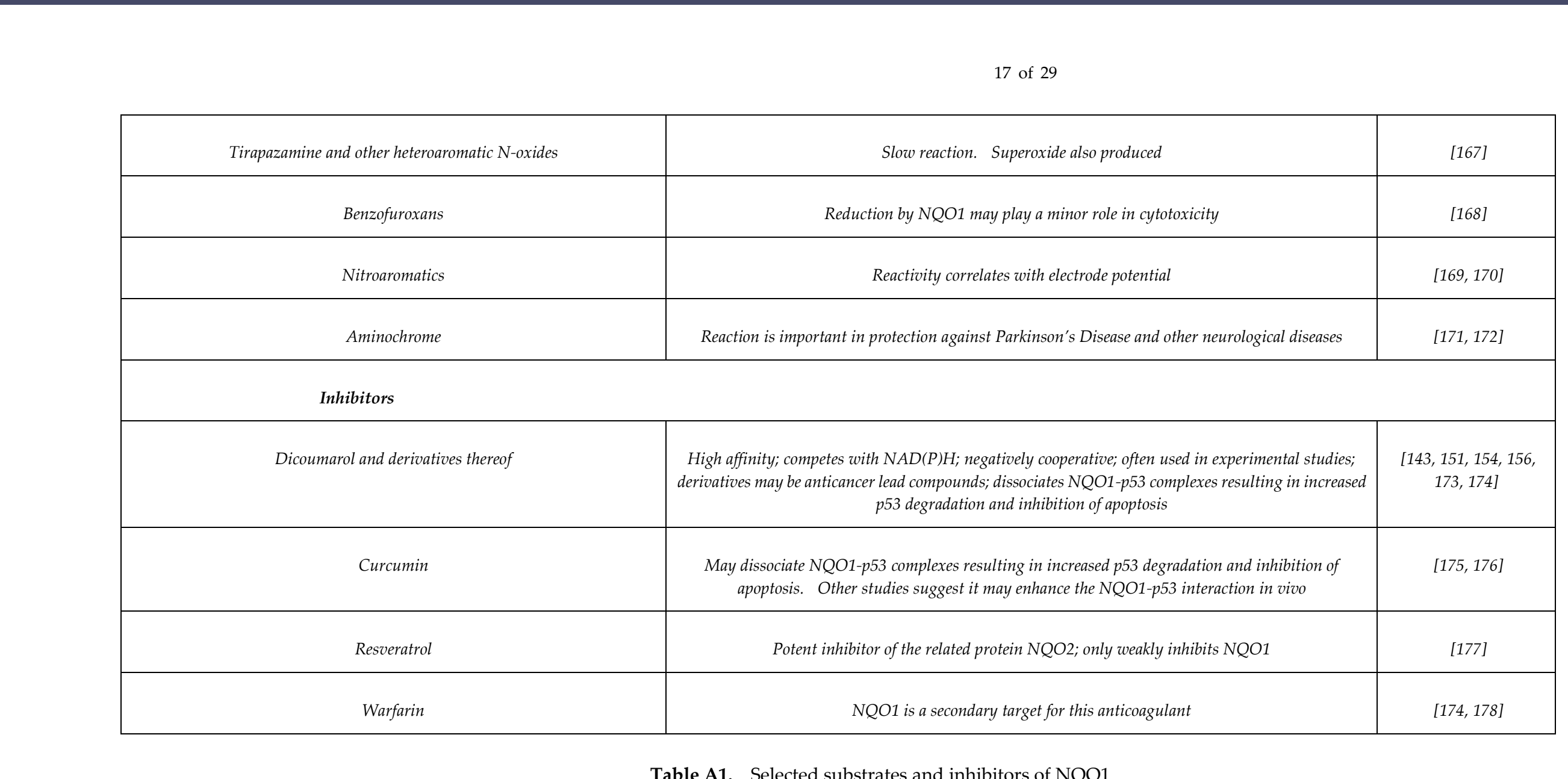

Table A1. Selected substrates and inhibitors of NQO1. \\ Preprints (www.preprints.org) | NOT PEER-REVIEWED | Posted: 18 March 2020 doi:10.20944/preprints202003.0265.v \\ Preprints (www.preprints.org) | NOT PEER-REVIEWED | Posted: 18 March $2020 \quad$ doi:10.20944/preprints202003.0285.v1}

(1)

Table A1. Select substas andinhitors of

.

17 of 29

(6)

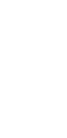
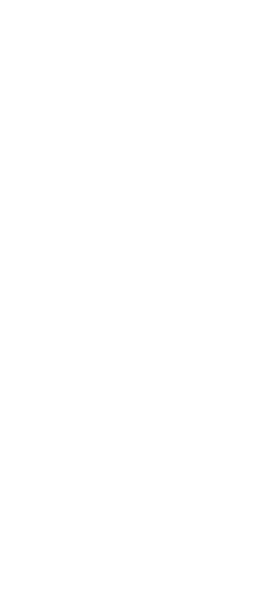

(a)


18 of 29

\begin{tabular}{|c|c|c|c|c|c|}
\hline Macromolecule & $\begin{array}{c}\text { Effect on partner } \\
\text { stability }\end{array}$ & Effect of NAD(P)H & Effect of dicoumarol & General comments & References \\
\hline$p 53$ & $\begin{array}{l}\text { Binds to, and stabilises, the } \\
\text { full-length protein, protecting it } \\
\text { from proteasomal degradation }\end{array}$ & $\begin{array}{l}\text { Increases affinity of } \\
\text { interaction. }\end{array}$ & Antagonises interaction. & $\begin{array}{l}\text { Interaction promotes p53-mediated apoptosis. } \\
\text { Dicoumarol down-regulates this by promoting release of } \\
\text { p53 from NQO1 and consequent degradation of p53. }\end{array}$ & $\begin{array}{c}{[117,143,153,179,} \\
180]\end{array}$ \\
\hline$p 73 \alpha$ & $\begin{array}{l}\text { Binds to, and stabilises, the } \\
\text { full-length protein, protecting it } \\
\text { from proteasomal degradation. }\end{array}$ & $\begin{array}{l}\text { Increases affinity of } \\
\text { interaction; effect not } \\
\text { observed with } \mathrm{NAD}^{+} \text {. }\end{array}$ & Antagonises interaction. & $\begin{array}{l}\text { Interaction promotes } p 73 \alpha \text {-mediated apoptosis. } \\
\text { Dicoumarol down-regulates this by promoting release of } \\
p 73 \alpha \text { from NQO1 and consequent degradation of } p 73 \alpha \text {. } \\
\text { No interaction with } p 73 \beta \text { which lacks a SAM domain at } \\
\text { the C-terminus. The SAM in } p 73 \alpha \text { is responsible for the } \\
\text { interaction. }\end{array}$ & {$[78,117]$} \\
\hline $\begin{array}{c}\text { Ornithine } \\
\text { decarboxylase }(O D C)\end{array}$ & $\begin{array}{l}\text { NQO1 binds to, and stabilises } \\
\text { ODC, preventing proteasomal } \\
\text { degradation }\end{array}$ & Not known. & Antagonises interaction & $\begin{array}{l}\text { ODC monomer (inactive) degradation is enhanced by } \\
\text { binding antizyme 1(AZ1) which targets the ODC/AZ1 } \\
\text { complex to the proteasome. NQO1 protects monomeric } \\
\text { ODC by binding the ODC/AZ1 heterodimer. }\end{array}$ & {$[181,182]$} \\
\hline $\begin{array}{l}\text { mRNA encoding } \\
\text { SERPINA1 } \\
\text { ( } \alpha \text {-1-antitrypsin })\end{array}$ & No effect on stability & Not known & Not known & $\begin{array}{c}\text { Does not affect the amount of } m R N A \text {, but does enhance the } \\
\text { translation by binding to 3'-UTR. This results in more } \\
\text { protein }\end{array}$ & [114] \\
\hline $\begin{array}{c}20 S \text { proteasomal } \\
\text { subunit }\end{array}$ & Not known & No effect & Not known & $\begin{array}{l}\text { NQO1 interacts with the proteasome and negatively } \\
\text { regulates proteolytic activity. NQO1-apo is degraded by } \\
\text { the proteasome. }\end{array}$ & [115] \\
\hline HIF-1 $\alpha$ & $\begin{array}{c}\text { NQO1 binds HIF- } 1 \alpha, \text { stabilises } \\
\text { it and prevent proteasomal } \\
\text { degradation }\end{array}$ & Not known & Not known & $\begin{array}{l}\text { Interaction occurs in cytoplasm. } \\
\text { NQO1 enhances transcription of HIF- } 1 \alpha \text { regulated genes, } \\
\text { presumably by increasing the amount of HIF-1 } \alpha \text {. } \\
\text { See also main text. }\end{array}$ & [74] \\
\hline Hsp70/HSPA4 & Interaction most likely occurs & Not known & Not known & NQO1-p.P187S only interacts very weakly. & [183] \\
\hline
\end{tabular}


20 of 29

\begin{tabular}{|c|c|c|c|c|c|}
\hline protein (Herp) & & & & & \\
\hline$P G C-1 \alpha$ & $\begin{array}{l}\text { Stabilises this intrinsically } \\
\text { disordered protein and protects } \\
\text { it from proteasomal } \\
\text { degradation. }\end{array}$ & Enhances interaction & Antagonises interaction & $\begin{array}{l}\text { Cellular levels of NQO1 and PGC-1 } \alpha \text { are correlated. } \\
\text { Stabilisation of PGC-1 } 1 \alpha \text { by NQO1 leads to induction of } \\
\text { genes encoding enzymes of gluconeogénesis. }\end{array}$ & [192] \\
\hline $\begin{array}{c}\text { RIL } \\
\text { (reversion-induced } \\
\text { LIM domain protein; } \\
\text { PDLIM4) }\end{array}$ & $\begin{array}{l}\text { NQO1 binds and stabilises } \\
\text { unstructured C-terminal región } \\
\text { of one alternately spliced } \\
\text { isoform (RILaltCterm) } \\
\text { protecting it from proteasomal } \\
\text { degradation. }\end{array}$ & Not known & $\begin{array}{l}\text { Increases RIL proteasomal } \\
\text { degradation, presumably by } \\
\text { antagonising RIL/NQO1 } \\
\text { interaction }\end{array}$ & $\begin{array}{l}\text { RILaltCterm accumulates in response to oxidative stress } \\
\text { and stimulates actin cytoskeleton rearrangement. }\end{array}$ & [193] \\
\hline 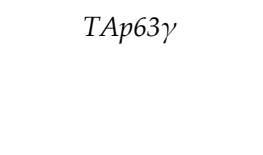 & $\begin{array}{c}\text { Stabilises TAp63y and protects } \\
\text { it from proteasomal } \\
\text { degradation. }\end{array}$ & Not known & Not known & $\begin{array}{l}\text { NQO1-p.P187S does not interact. } \\
\text { Interaction occurs in response to genotoxic stress. }\end{array}$ & [194] \\
\hline
\end{tabular}

Table A2. Macromolecular binding partners of NQO1 and effects of ligand binding. 


\section{References}

1. Semenza, G.L. Hypoxia-inducible factors in physiology and medicine. Cell 2012, 148, 399-408.

2. Nakazawa, M.S.; Keith, B.; Simon, M.C. Oxygen availability and metabolic adaptations. Nat Rev Cancer 2016, 16, 663-673.

3. Wang, G.L.; Jiang, B.H.; Rue, E.A.; Semenza, G.L. Hypoxia-inducible factor 1 is a basic-helix-loop-helix-PAS heterodimer regulated by cellular O2 tension. Proc Natl Acad Sci U S A 1995, 92, 5510-5514.

4. Yee Koh, M.; Spivak-Kroizman, T.R.; Powis, G. HIF-1 regulation: not so easy come, easy go. Trends Biochem Sci 2008, 33, 526-534.

5. Taylor, C.T.; Doherty, G.; Fallon, P.G.; Cummins, E.P. Hypoxia-dependent regulation of inflammatory pathways in immune cells. J Clin Invest 2016, 126, 3716-3724.

6. Jiang, B.H.; Rue, E.; Wang, G.L.; Roe, R.; Semenza, G.L. Dimerization, DNA binding, and transactivation properties of hypoxia-inducible factor 1. J Biol Chem 1996, 271, 17771-17778.

7. Makino, Y.; Cao, R.; Svensson, K.; Bertilsson, G.; Asman, M.; Tanaka, H.; Cao, Y.; Berkenstam, A.; Poellinger, L. Inhibitory PAS domain protein is a negative regulator of hypoxia-inducible gene expression. Nature 2001, 414, 550-554.

8. Marti, H.H.; Katschinski, D.M.; Wagner, K.F.; Schaffer, L.; Stier, B.; Wenger, R.H. Isoform-specific expression of hypoxia-inducible factor-1alpha during the late stages of mouse spermiogenesis. Mol Endocrinol 2002, 16, 234-243.

9. Maynard, M.A.; Qi, H.; Chung, J.; Lee, E.H.; Kondo, Y.; Hara, S.; Conaway, R.C.; Conaway, J.W.; Ohh, M. Multiple splice variants of the human HIF-3 alpha locus are targets of the von Hippel-Lindau E3 ubiquitin ligase complex. J Biol Chem 2003, 278, 11032-11040.

10. Depping, R.; Hagele, S.; Wagner, K.F.; Wiesner, R.J.; Camenisch, G.; Wenger, R.H.; Katschinski, D.M. A dominant-negative isoform of hypoxia-inducible factor- 1 alpha specifically expressed in human testis. Biol Reprod 2004, 71, 331-339.

11. Kallio, P.J.; Okamoto, K.; O'Brien, S.; Carrero, P.; Makino, Y.; Tanaka, H.; Poellinger, L. Signal transduction in hypoxic cells: inducible nuclear translocation and recruitment of the CBP/p300 coactivator by the hypoxia-inducible factor-1alpha. EMBO J 1998, 17, 6573-6586.

12. Salceda, S.; Caro, J. Hypoxia-inducible factor 1alpha (HIF-1alpha) protein is rapidly degraded by the ubiquitin-proteasome system under normoxic conditions. Its stabilization by hypoxia depends on redox-induced changes. J Biol Chem 1997, 272, 22642-22647.

13. Huang, L.E.; Gu, J.; Schau, M.; Bunn, H.F. Regulation of hypoxia-inducible factor 1alpha is mediated by an O2-dependent degradation domain via the ubiquitin-proteasome pathway. Proc Natl Acad Sci U S A 1998, 95, 7987-7992.

14. Jiang, B.H.; Zheng, J.Z.; Leung, S.W.; Roe, R.; Semenza, G.L. Transactivation and inhibitory domains of hypoxia-inducible factor 1alpha. Modulation of transcriptional activity by oxygen tension. J Biol Chem 1997, 272, 19253-19260.

15. Yamashita, K.; Discher, D.J.; Hu, J.; Bishopric, N.H.; Webster, K.A. Molecular regulation of the endothelin-1 gene by hypoxia. Contributions of hypoxia-inducible factor-1, activator protein-1, GATA-2, AND p300/CBP. J Biol Chem 2001, 276, 12645-12653.

16. Ivan, M.; Kondo, K.; Yang, H.; Kim, W.; Valiando, J.; Ohh, M.; Salic, A.; Asara, J.M.; Lane, W.S.; Kaelin, W.G., Jr. HIFalpha targeted for VHL-mediated destruction by proline hydroxylation: implications for O2 sensing. Science 2001, 292, 464-468.

17. Jaakkola, P.; Mole, D.R.; Tian, Y.M.; Wilson, M.I.; Gielbert, J.; Gaskell, S.J.; von Kriegsheim, A.; Hebestreit, H.F.; Mukherji, M.; Schofield, C.J.; Maxwell, P.H.; Pugh, C.W.; Ratcliffe, P.J. Targeting of HIF-alpha to the von Hippel-Lindau ubiquitylation complex by O2-regulated prolyl hydroxylation. Science 2001, 292, 468-472.

18. Masson, N.; Willam, C.; Maxwell, P.H.; Pugh, C.W.; Ratcliffe, P.J. Independent function of two destruction domains in hypoxia-inducible factor-alpha chains activated by prolyl hydroxylation. $E M B O J$ 2001, 20, 5197-5206.

19. Maxwell, P.H.; Wiesener, M.S.; Chang, G.W.; Clifford, S.C.; Vaux, E.C.; Cockman, M.E.; Wykoff, C.C.; Pugh, C.W.; Maher, E.R.; Ratcliffe, P.J. The tumour suppressor protein VHL targets hypoxia-inducible factors for oxygen-dependent proteolysis. Nature 1999, 399, 271-275.

20. Cockman, M.E.; Masson, N.; Mole, D.R.; Jaakkola, P.; Chang, G.W.; Clifford, S.C.; Maher, E.R.; Pugh, C.W.; Ratcliffe, P.J.; Maxwell, P.H. Hypoxia inducible factor-alpha binding and ubiquitylation by the von Hippel-Lindau tumor suppressor protein. J Biol Chem 2000, 275, 25733-25741. 
21. Kamura, T.; Sato, S.; Iwai, K.; Czyzyk-Krzeska, M.; Conaway, R.C.; Conaway, J.W. Activation of HIF1alpha ubiquitination by a reconstituted von Hippel-Lindau (VHL) tumor suppressor complex. Proc Natl Acad Sci U S A 2000, 97, 10430-10435.

22. Ohh, M.; Park, C.W.; Ivan, M.; Hoffman, M.A.; Kim, T.Y.; Huang, L.E.; Pavletich, N.; Chau, V.; Kaelin, W.G. Ubiquitination of hypoxia-inducible factor requires direct binding to the beta-domain of the von Hippel-Lindau protein. Nat Cell Biol 2000, 2, 423-427.

23. Mahon, P.C.; Hirota, K.; Semenza, G.L. FIH-1: a novel protein that interacts with HIF-1alpha and VHL to mediate repression of HIF-1 transcriptional activity. Genes Dev 2001, 15, 2675-2686.

24. Hagen, T.; Taylor, C.T.; Lam, F.; Moncada, S. Redistribution of intracellular oxygen in hypoxia by nitric oxide: effect on HIF1alpha. Science 2003, 302, 1975-1978.

25. Doege, K.; Heine, S.; Jensen, I.; Jelkmann, W.; Metzen, E. Inhibition of mitochondrial respiration elevates oxygen concentration but leaves regulation of hypoxia-inducible factor (HIF) intact. Blood 2005, 106, $2311-2317$.

26. Selak, M.A.; Armour, S.M.; MacKenzie, E.D.; Boulahbel, H.; Watson, D.G.; Mansfield, K.D.; Pan, Y.; Simon, M.C.; Thompson, C.B.; Gottlieb, E. Succinate links TCA cycle dysfunction to oncogenesis by inhibiting HIF-alpha prolyl hydroxylase. Cancer Cell 2005, 7, 77-85.

27. Chandel, N.S.; McClintock, D.S.; Feliciano, C.E.; Wood, T.M.; Melendez, J.A.; Rodriguez, A.M.; Schumacker, P.T. Reactive oxygen species generated at mitochondrial complex III stabilize hypoxia-inducible factor-1alpha during hypoxia: a mechanism of O2 sensing. J Biol Chem 2000, 275, 25130-25138.

28. Agani, F.H.; Pichiule, P.; Chavez, J.C.; LaManna, J.C. The role of mitochondria in the regulation of hypoxia-inducible factor 1 expression during hypoxia. J Biol Chem 2000, 275, 35863-35867.

29. Dalgard, C.L.; Lu, H.; Mohyeldin, A.; Verma, A. Endogenous 2-oxoacids differentially regulate expression of oxygen sensors. Biochem J 2004, 380, 419-424.

30. Isaacs, J.S.; Jung, Y.J.; Mole, D.R.; Lee, S.; Torres-Cabala, C.; Chung, Y.L.; Merino, M.; Trepel, J.; Zbar, B.; Toro, J.; Ratcliffe, P.J.; Linehan, W.M.; Neckers, L. HIF overexpression correlates with biallelic loss of fumarate hydratase in renal cancer: novel role of fumarate in regulation of HIF stability. Cancer Cell 2005, 8, 143-153.

31. Koivunen, P.; Hirsila, M.; Remes, A.M.; Hassinen, I.E.; Kivirikko, K.I.; Myllyharju, J. Inhibition of hypoxia-inducible factor (HIF) hydroxylases by citric acid cycle intermediates: possible links between cell metabolism and stabilization of HIF. J Biol Chem 2007, 282, 4524-4532.

32. Chandel, N.S.; Maltepe, E.; Goldwasser, E.; Mathieu, C.E.; Simon, M.C.; Schumacker, P.T. Mitochondrial reactive oxygen species trigger hypoxia-induced transcription. Proc Natl Acad Sci U S A 1998, 95, 11715-11720.

33. Brunelle, J.K.; Bell, E.L.; Quesada, N.M.; Vercauteren, K.; Tiranti, V.; Zeviani, M.; Scarpulla, R.C.; Chandel, N.S. Oxygen sensing requires mitochondrial ROS but not oxidative phosphorylation. Cell Metab 2005, 1, 409-414.

34. Guzy, R.D.; Hoyos, B.; Robin, E.; Chen, H.; Liu, L.; Mansfield, K.D.; Simon, M.C.; Hammerling, U.; Schumacker, P.T. Mitochondrial complex III is required for hypoxia-induced ROS production and cellular oxygen sensing. Cell Metab 2005, 1, 401-408.

35. Mansfield, K.D.; Guzy, R.D.; Pan, Y.; Young, R.M.; Cash, T.P.; Schumacker, P.T.; Simon, M.C. Mitochondrial dysfunction resulting from loss of cytochrome c impairs cellular oxygen sensing and hypoxic HIF-alpha activation. Cell Metab 2005, 1, 393-399.

36. Feldser, D.; Agani, F.; Iyer, N.V.; Pak, B.; Ferreira, G.; Semenza, G.L. Reciprocal positive regulation of hypoxia-inducible factor 1alpha and insulin-like growth factor 2. Cancer Res 1999, 59, 3915-3918.

37. Forsythe, J.A.; Jiang, B.H.; Iyer, N.V.; Agani, F.; Leung, S.W.; Koos, R.D.; Semenza, G.L. Activation of vascular endothelial growth factor gene transcription by hypoxia-inducible factor 1. Mol Cell Biol 1996, 16, 4604-4613.

38. Zelzer, E.; Levy, Y.; Kahana, C.; Shilo, B.Z.; Rubinstein, M.; Cohen, B. Insulin induces transcription of target genes through the hypoxia-inducible factor HIF-1alpha/ARNT. EMBO J 1998, 17, 5085-5094.

39. Jung, Y.; Isaacs, J.S.; Lee, S.; Trepel, J.; Liu, Z.G.; Neckers, L. Hypoxia-inducible factor induction by tumour necrosis factor in normoxic cells requires receptor-interacting protein-dependent nuclear factor kappa B activation. Biochem J 2003, 370, 1011-1017.

40. Jung, Y.J.; Isaacs, J.S.; Lee, S.; Trepel, J.; Neckers, L. IL-1beta-mediated up-regulation of HIF-1alpha via an NFkappaB/COX-2 pathway identifies HIF-1 as a critical link between inflammation and oncogenesis. FASEB J 2003, 17, 2115-2117.

41. Albina, J.E.; Mastrofrancesco, B.; Vessella, J.A.; Louis, C.A.; Henry, W.L., Jr.; Reichner, J.S. HIF-1 expression in healing wounds: HIF-1alpha induction in primary inflammatory cells by TNF-alpha. Am J Physiol Cell Physiol 2001, 281, C1971-1977.

42. Gingras, A.C.; Raught, B.; Sonenberg, N. Regulation of translation initiation by FRAP/mTOR. Genes Dev 2001, 15, 807-826. 
43. Sang, N.; Stiehl, D.P.; Bohensky, J.; Leshchinsky, I.; Srinivas, V.; Caro, J. MAPK signaling up-regulates the activity of hypoxia-inducible factors by its effects on p300. J Biol Chem 2003, 278, 14013-14019.

44. Sonenberg, N.; Hinnebusch, A.G. New modes of translational control in development, behavior, and disease. Mol Cell 2007, 28, 721-729.

45. Richard, D.E.; Berra, E.; Gothie, E.; Roux, D.; Pouyssegur, J. p42/p44 mitogen-activated protein kinases phosphorylate hypoxia-inducible factor 1alpha (HIF-1alpha) and enhance the transcriptional activity of HIF-1. J Biol Chem 1999, 274, 32631-32637.

46. Chen, D.; Li, M.; Luo, J.; Gu, W. Direct interactions between HIF-1 alpha and Mdm2 modulate p53 function. J Biol Chem 2003, 278, 13595-13598.

47. Schmid, T.; Zhou, J.; Kohl, R.; Brune, B. p300 relieves p53-evoked transcriptional repression of hypoxia-inducible factor-1 (HIF-1). Biochem J 2004, 380, 289-295.

48. Ravi, R.; Mookerjee, B.; Bhujwalla, Z.M.; Sutter, C.H.; Artemov, D.; Zeng, Q.; Dillehay, L.E.; Madan, A.; Semenza, G.L.; Bedi, A. Regulation of tumor angiogenesis by p53-induced degradation of hypoxia-inducible factor 1alpha. Genes Dev 2000, 14, 34-44.

49. Isaacs, J.S.; Jung, Y.J.; Mimnaugh, E.G.; Martinez, A.; Cuttitta, F.; Neckers, L.M. Hsp90 regulates a von Hippel Lindau-independent hypoxia-inducible factor-1 alpha-degradative pathway. J Biol Chem 2002, 277, 29936-29944.

50. Kong, X.; Lin, Z.; Liang, D.; Fath, D.; Sang, N.; Caro, J. Histone deacetylase inhibitors induce VHL and ubiquitin-independent proteasomal degradation of hypoxia-inducible factor 1alpha. Mol Cell Biol 2006, 26, 2019-2028.

51. Gradin, K.; McGuire, J.; Wenger, R.H.; Kvietikova, I.; fhitelaw, M.L.; Toftgard, R.; Tora, L.; Gassmann, M.; Poellinger, L. Functional interference between hypoxia and dioxin signal transduction pathways: competition for recruitment of the Arnt transcription factor. Mol Cell Biol 1996, 16, 5221-5231.

52. Hanahan, D.; Weinberg, R.A. Hallmarks of cancer: the next generation. Cell 2011, 144, 646-674.

53. Harris, A.L. Hypoxia--a key regulatory factor in tumour growth. Nat Rev Cancer 2002, 2, 38-47.

54. Thomlinson, R.H.; Gray, L.H. The histological structure of some human lung cancers and the possible implications for radiotherapy. Br J Cancer 1955, 9, 539-549.

55. Moulder, J.E.; Rockwell, S. Hypoxic fractions of solid tumors: experimental techniques, methods of analysis, and a survey of existing data. Int J Radiat Oncol Biol Phys 1984, 10, 695-712.

56. Semenza, G.L. Targeting HIF-1 for cancer therapy. Nat Rev Cancer 2003, 3, 721-732.

57. Schito, L.; Semenza, G.L. Hypoxia-Inducible Factors: Master Regulators of Cancer Progression. Trends Cancer 2016, 2, 758-770.

58. Semenza, G.L. HIF-1 mediates metabolic responses to intratumoral hypoxia and oncogenic mutations. $J$ Clin Invest 2013, 123, 3664-3671.

59. Warburg, O. On respiratory impairment in cancer cells. Science 1956, 124, 269-270.

60. Hayashi, Y.; Yokota, A.; Harada, H.; Huang, G. Hypoxia/pseudohypoxia-mediated activation of hypoxia-inducible factor-1alpha in cancer. Cancer Sci 2019, 110, 1510-1517.

61. Pan-cancer analysis of whole genomes. Nature 2020, 578, 82-93.

62. Chappell, J.C.; Payne, L.B.; Rathmell, W.K. Hypoxia, angiogenesis, and metabolism in the hereditary kidney cancers. J Clin Invest 2019, 129, 442-451.

63. Schmidt, L.S.; Linehan, W.M. Genetic predisposition to kidney cancer. Semin Oncol 2016, 43, 566-574.

64. Semenza, G.L.; Roth, P.H.; Fang, H.M.; Wang, G.L. Transcriptional regulation of genes encoding glycolytic enzymes by hypoxia-inducible factor 1. J Biol Chem 1994, 269, 23757-23763.

65. Zhang, H.; Bosch-Marce, M.; Shimoda, L.A.; Tan, Y.S.; Baek, J.H.; Wesley, J.B.; Gonzalez, F.J.; Semenza, G.L. Mitochondrial autophagy is an HIF-1-dependent adaptive metabolic response to hypoxia. J Biol Chem 2008, 283, 10892-10903.

66. Bellot, G.; Garcia-Medina, R.; Gounon, P.; Chiche, J.; Roux, D.; Pouyssegur, J.; Mazure, N.M. Hypoxia-induced autophagy is mediated through hypoxia-inducible factor induction of BNIP3 and BNIP3L via their BH3 domains. Mol Cell Biol 2009, 29, 2570-2581.

67. Favaro, E.; Ramachandran, A.; McCormick, R.; Gee, H.; Blancher, C.; Crosby, M.; Devlin, C.; Blick, C.; Buffa, F.; Li, J.L.; Vojnovic, B.; Pires das Neves, R.; Glazer, P.; Iborra, F.; Ivan, M.; Ragoussis, J.; Harris, A.L. MicroRNA-210 regulates mitochondrial free radical response to hypoxia and krebs cycle in cancer cells by targeting iron sulfur cluster protein ISCU. PLoS One 2010, 5, e10345.

68. Luo, W.; Hu, H.; Chang, R.; Zhong, J.; Knabel, M.; O'Meally, R.; Cole, R.N.; Pandey, A.; Semenza, G.L. Pyruvate kinase M2 is a PHD3-stimulated coactivator for hypoxia-inducible factor 1. Cell 2011, 145, 732-744.

69. Kaelin, W.G., Jr. The VHL Tumor Suppressor Gene: Insights into Oxygen Sensing and Cancer. Trans Am Clin Climatol Assoc 2017, 128, 298-307. 
70. Kaelin, W.G., Jr. The von Hippel-Lindau tumor suppressor gene and kidney cancer. Clin Cancer Res 2004, 10, 6290S-6295S.

71. Chappell, J.C.; Cluceru, J.G.; Nesmith, J.E.; Mouillesseaux, K.P.; Bradley, V.B.; Hartland, C.M.; Hashambhoy-Ramsay, Y.L.; Walpole, J.; Peirce, S.M.; Mac Gabhann, F.; Bautch, V.L. Flt-1 (VEGFR-1) coordinates discrete stages of blood vessel formation. Cardiovasc Res 2016, 111, 84-93.

72. Tamaskar, I.; Dhillon, J.; Pili, R. Resistance to angiogenesis inhibitors in renal cell carcinoma. Clin Adv Hematol Oncol 2011, 9, 101-110.

73. Cui, J.; Jiang, H. Prediction of postoperative survival of triple-negative breast cancer based on nomogram model combined with expression of HIF-1alpha and c-myc. Medicine (Baltimore) 2019, 98, e17370.

74. Oh, E.T.; Kim, J.W.; Kim, J.M.; Kim, S.J.; Lee, J.S.; Hong, S.S.; Goodwin, J.; Ruthenborg, R.J.; Jung, M.G.; Lee, H.J.; Lee, C.H.; Park, E.S.; Kim, C.; Park, H.J. NQO1 inhibits proteasome-mediated degradation of HIF-1alpha. Nat Commun 2016, 7, 13593.

75. Li, R.; Bianchet, M.A.; Talalay, P.; Amzel, L.M. The three-dimensional structure of NAD(P)H:quinone reductase, a flavoprotein involved in cancer chemoprotection and chemotherapy: mechanism of the two-electron reduction. Proc Natl Acad Sci U S A 1995, 92, 8846-8850.

76. Beaver, S.K.; Mesa-Torres, N.; Pey, A.L.; Timson, D.J. NQO1: A target for the treatment of cancer and neurological diseases, and a model to understand loss of function disease mechanisms. Biochim Biophys Acta Proteins Proteom 2019, 1867, 663-676.

77. Pey, A.L.; Megarity, C.F.; Medina-Carmona, E.; Timson, D.J. Natural Small Molecules as Stabilizers and Activators of Cancer-Associated NQO1 Polymorphisms. Curr Drug Targets 2016, 17, 1506-1514.

78. Medina-Carmona, E.; Neira, J.L.; Salido, E.; Fuchs, J.E.; Palomino-Morales, R.; Timson, D.J.; Pey, A.L. Site-to-site interdomain communication may mediate different loss-of-function mechanisms in a cancer-associated NQO1 polymorphism. Scientific Reports 2017, 7, 44352.

79. Lienhart, W.D.; Gudipati, V.; Uhl, M.K.; Binter, A.; Pulido, S.A.; Saf, R.; Zangger, K.; Gruber, K.; Macheroux, P. Collapse of the native structure caused by a single amino acid exchange in human NAD(P)H:quinone oxidoreductase(1.). FEBS J 2014, 281, 4691-4704.

80. Chen, S.; Deng, P.S.; Bailey, J.M.; Swiderek, K.M. A two-domain structure for the two subunits of NAD(P)H:quinone acceptor oxidoreductase. Protein Sci 1994, 3, 51-57.

81. Faig, M.; Bianchet, M.A.; Talalay, P.; Chen, S.; Winski, S.; Ross, D.; Amzel, L.M. Structures of recombinant human and mouse $\mathrm{NAD}(\mathrm{P}) \mathrm{H}$ :quinone oxidoreductases: species comparison and structural changes with substrate binding and release. Proc Natl Acad Sci U S A 2000, 97, 3177-3182.

82. Anusevicius, Z.; Sarlauskas, J.; Cenas, N. Two-electron reduction of quinones by rat liver $\mathrm{NAD}(\mathrm{P}) \mathrm{H}$ :quinone oxidoreductase: quantitative structure-activity relationships. Arch Biochem Biophys 2002, 404, 254-262.

83. Ingram, B.O.; Turbyfill, J.L.; Bledsoe, P.J.; Jaiswal, A.K.; Stafford, D.W. Assessment of the contribution of $\mathrm{NAD}(\mathrm{P}) \mathrm{H}$-dependent quinone oxidoreductase 1 (NQO1) to the reduction of vitamin $\mathrm{K}$ in wild-type and NQO1-deficient mice. Biochem J 2013, 456, 47-54.

84. Landi, L.; Fiorentini, D.; Galli, M.C.; Segura-Aguilar, J.; Beyer, R.E. DT-Diaphorase maintains the reduced state of ubiquinones in lipid vesicles thereby promoting their antioxidant function. Free Radic Biol Med 1997, 22, 329-335.

85. Siegel, D.; Bolton, E.M.; Burr, J.A.; Liebler, D.C.; Ross, D. The reduction of alpha-tocopherolquinone by human $\mathrm{NAD}(\mathrm{P}) \mathrm{H}$ : quinone oxidoreductase: the role of alpha-tocopherolhydroquinone as a cellular antioxidant. Mol Pharmacol 1997, 52, 300-305.

86. Siegel, D.; Gustafson, D.L.; Dehn, D.L.; Han, J.Y.; Boonchoong, P.; Berliner, L.J.; Ross, D. NAD(P)H:quinone oxidoreductase 1: role as a superoxide scavenger. Mol Pharmacol 2004, 65, 1238-1247.

87. Timson, D.J. Dicoumarol: A Drug which Hits at Least Two Very Different Targets in Vitamin K Metabolism. Curr Drug Targets 2017, 18, 500-510.

88. Cullen, J.J.; Hinkhouse, M.M.; Grady, M.; Gaut, A.W.; Liu, J.; Zhang, Y.P.; Weydert, C.J.; Domann, F.E.; Oberley, L.W. Dicumarol inhibition of NADPH:quinone oxidoreductase induces growth inhibition of pancreatic cancer via a superoxide-mediated mechanism. Cancer Res 2003, 63, 5513-5520.

89. Luo, S.; Su Kang, S.; Wang, Z.H.; Liu, X.; Day, J.X.; Wu, Z.; Peng, J.; Xiang, D.; Springer, W.; Ye, K. Akt Phosphorylates NQO1 and Triggers its Degradation, Abolishing its Antioxidative Activities in Parkinson's Disease. J Neurosci 2019, 39, 7291-7305.

90. Medina-Carmona, E.; Rizzuti, B.; Martin-Escolano, R.; Pacheco-Garcia, J.L.; Mesa-Torres, N.; Neira, J.L.; Guzzi, R.; Pey, A.L. Phosphorylation compromises FAD binding and intracellular stability of wild-type and cancer-associated NQO1: Insights into flavo-proteome stability. Int J Biol Macromol 2019, 125, 1275-1288. 
91. Ross, D.; Kepa, J.K.; Winski, S.L.; Beall, H.D.; Anwar, A.; Siegel, D. NAD(P)H:quinone oxidoreductase 1 (NQO1): chemoprotection, bioactivation, gene regulation and genetic polymorphisms. Chem Biol Interact 2000, 129, 77-97.

92. Rushmore, T.H.; Morton, M.R.; Pickett, C.B. The antioxidant responsive element. Activation by oxidative stress and identification of the DNA consensus sequence required for functional activity. J Biol Chem 1991, 266, 11632-11639.

93. Nioi, P.; Hayes, J.D. Contribution of $\mathrm{NAD}(\mathrm{P}) \mathrm{H}$ :quinone oxidoreductase 1 to protection against carcinogenesis, and regulation of its gene by the Nrf2 basic-region leucine zipper and the arylhydrocarbon receptor basic helix-loop-helix transcription factors. Mutat Res 2004, 555, 149-171.

94. Brauze, D.; Widerak, M.; Cwykiel, J.; Szyfter, K.; Baer-Dubowska, W. The effect of aryl hydrocarbon receptor ligands on the expression of AhR, AhRR, ARNT, Hif1alpha, CYP1A1 and NQO1 genes in rat liver. Toxicol Lett 2006, 167, 212-220.

95. Itoh, K.; Wakabayashi, N.; Katoh, Y.; Ishii, T.; Igarashi, K.; Engel, J.D.; Yamamoto, M. Keap1 represses nuclear activation of antioxidant responsive elements by Nrf2 through binding to the amino-terminal Neh2 domain. Genes Dev 1999, 13, 76-86.

96. Furukawa, M.; Xiong, Y. BTB protein Keap1 targets antioxidant transcription factor Nrf2 for ubiquitination by the Cullin 3-Roc1 ligase. Mol Cell Biol 2005, 25, 162-171.

97. Dinkova-Kostova, A.T.; Holtzclaw, W.D.; Cole, R.N.; Itoh, K.; Wakabayashi, N.; Katoh, Y.; Yamamoto, M.; Talalay, P. Direct evidence that sulfhydryl groups of Keap1 are the sensors regulating induction of phase 2 enzymes that protect against carcinogens and oxidants. Proc Natl Acad Sci U S A 2002, 99, 11908-11913.

98. Motohashi, H.; O'Connor, T.; Katsuoka, F.; Engel, J.D.; Yamamoto, M. Integration and diversity of the regulatory network composed of Maf and CNC families of transcription factors. Gene 2002, 294, 1-12.

99. Tonelli, C.; Chio, I.I.C.; Tuveson, D.A. Transcriptional Regulation by Nrf2. Antioxid Redox Signal 2018, 29, 1727-1745.

100. Sun, Z.; Chin, Y.E.; Zhang, D.D. Acetylation of Nrf2 by p300/CBP augments promoter-specific DNA binding of Nrf2 during the antioxidant response. Mol Cell Biol 2009, 29, 2658-2672.

101. Sekine, H.; Okazaki, K.; Ota, N.; Shima, H.; Katoh, Y.; Suzuki, N.; Igarashi, K.; Ito, M.; Motohashi, H.; Yamamoto, M. The Mediator Subunit MED16 Transduces NRF2-Activating Signals into Antioxidant Gene Expression. Mol Cell Biol 2016, 36, 407-420.

102. Hayes, J.D.; Dinkova-Kostova, A.T. The Nrf2 regulatory network provides an interface between redox and intermediary metabolism. Trends Biochem Sci 2014, 39, 199-218.

103. Wu, K.C.; Cui, J.Y.; Klaassen, C.D. Beneficial role of Nrf2 in regulating NADPH generation and consumption. Toxicol Sci 2011, 123, 590-600.

104. Valerio, L.G., Jr.; Kepa, J.K.; Pickwell, G.V.; Quattrochi, L.C. Induction of human NAD(P)H:quinone oxidoreductase (NQO1) gene expression by the flavonol quercetin. Toxicol Lett 2001, 119, 49-57.

105. Hsieh, T.C.; Lu, X.; Wang, Z.; Wu, J.M. Induction of quinone reductase NQO1 by resveratrol in human K562 cells involves the antioxidant response element ARE and is accompanied by nuclear translocation of transcription factor Nrf2. Med Chem 2006, 2, 275-285.

106. Waleh, N.S.; Calaoagan, J.; Murphy, B.J.; Knapp, A.M.; Sutherland, R.M.; Laderoute, K.R. The redox-sensitive human antioxidant responsive element induces gene expression under low oxygen conditions. Carcinogenesis 1998, 19, 1333-1337.

107. O'Dwyer, P.J.; Yao, K.S.; Ford, P.; Godwin, A.K.; Clayton, M. Effects of hypoxia on detoxicating enzyme activity and expression in HT29 colon adenocarcinoma cells. Cancer Res 1994, 54, 3082-3087.

108. Stark, C.; Breitkreutz, B.J.; Reguly, T.; Boucher, L.; Breitkreutz, A.; Tyers, M. BioGRID: a general repository for interaction datasets. Nucleic Acids Res 2006, 34, D535-539.

109. Beischlag, T.V.; Luis Morales, J.; Hollingshead, B.D.; Perdew, G.H. The aryl hydrocarbon receptor complex and the control of gene expression. Crit Rev Eukaryot Gene Expr 2008, 18, 207-250.

110. Rowlands, J.C.; Gustafsson, J.A. Aryl hydrocarbon receptor-mediated signal transduction. Crit Rev Toxicol 1997, 27, 109-134.

111. Ma, Q.; Kinneer, K.; Bi, Y.; Chan, J.Y.; Kan, Y.W. Induction of murine NAD(P)H:quinone oxidoreductase by 2,3,7,8-tetrachlorodibenzo-p-dioxin requires the CNC (cap ' $n$ ' collar) basic leucine zipper transcription factor Nrf2 (nuclear factor erythroid 2-related factor 2): cross-interaction between AhR (aryl hydrocarbon receptor) and Nrf2 signal transduction. Biochem J 2004, 377, 205-213.

112. Gassmann, M.; Kvietikova, I.; Rolfs, A.; Wenger, R.H. Oxygen- and dioxin-regulated gene expression in mouse hepatoma cells. Kidney Int 1997, 51, 567-574.

113. Yeligar, S.M.; Machida, K.; Kalra, V.K. Ethanol-induced HO-1 and NQO1 are differentially regulated by HIF-1alpha and Nrf2 to attenuate inflammatory cytokine expression. J Biol Chem 2010, 285, 35359-35373. 
114. Di Francesco, A.; Di Germanio, C.; Panda, A.C.; Huynh, P.; Peaden, R.; Navas-Enamorado, I.; Bastian, P.; Lehrmann, E.; Diaz-Ruiz, A.; Ross, D.; Siegel, D.; Martindale, J.L.; Bernier, M.; Gorospe, M.; Abdelmohsen, K.; de Cabo, R. Novel RNA-binding activity of NQO1 promotes SERPINA1 mRNA translation. Free Radic Biol Med 2016, 99, 225-233.

115. Moscovitz, O.; Tsvetkov, P.; Hazan, N.; Michaelevski, I.; Keisar, H.; Ben-Nissan, G.; Shaul, Y.; Sharon, M. A mutually inhibitory feedback loop between the $20 \mathrm{~S}$ proteasome and its regulator, NQO1. Mol Cell 2012, 47, 76-86.

116. Martinez-Limon, A.; Alriquet, M.; Lang, W.H.; Calloni, G.; Wittig, I.; Vabulas, R.M. Recognition of enzymes lacking bound cofactor by protein quality control. Proc Natl Acad Sci U S A 2016, 113, 12156-12161.

117. Asher, G.; Tsvetkov, P.; Kahana, C.; Shaul, Y. A mechanism of ubiquitin-independent proteasomal degradation of the tumor suppressors p53 and p73. Genes Dev 2005, 19, 316-321.

118. Siegel, D.; Dehn, D.D.; Bokatzian, S.S.; Quinn, K.; Backos, D.S.; Di Francesco, A.; Bernier, M.; Reisdorph, N.; de Cabo, R.; Ross, D. Redox modulation of NQO1. PLoS One 2018, 13, e0190717.

119. Medina-Carmona, E.; Palomino-Morales, R.J.; Fuchs, J.E.; Padín-Gonzalez, E.; Mesa-Torres, N.; Salido, E.; Timson, D.J.; Pey, A.L. Conformational dynamics is key to understanding loss-of-function of NQO1 cancer-associated polymorphisms and its correction by pharmacological ligands. Scientific Reports 2016, 6, 20331.

120. Medina-Carmona, E.; Fuchs, J.E.; Gavira, J.A.; Mesa-Torres, N.; Neira, J.L.; Salido, E.; Palomino-Morales, R.; Burgos, M.; Timson, D.J.; Pey, A.L. Enhanced vulnerability of human proteins towards disease-associated inactivation through divergent evolution. Human Molecular Genetics 2017, 26, 3531-3544.

121. Pey, A.L. Anion-specific interaction with human NQO1 inhibits flavin binding. Int J Biol Macromol 2019, 126, 1223-1233.

122. Pey, A.L. Biophysical and functional perturbation analyses at cancer-associated P187 and K240 sites of the multifunctional NADP(H):quinone oxidoreductase 1. Int J Biol Macromol 2018, 118, 1912-1923.

123. Siegel, D.; Anwar, A.; Winski, S.L.; Kepa, J.K.; Zolman, K.L.; Ross, D. Rapid polyubiquitination and proteasomal degradation of a mutant form of $\mathrm{NAD}(\mathrm{P}) \mathrm{H}$ :quinone oxidoreductase 1. Mol Pharmacol 2001, 59, 263-268.

124. Diaz-Ruiz, A.; Lanasa, M.; Garcia, J.; Mora, H.; Fan, F.; Martin-Montalvo, A.; Di Francesco, A.; Calvo-Rubio, M.; Salvador-Pascual, A.; Aon, M.A.; Fishbein, K.W.; Pearson, K.J.; Villalba, J.M.; Navas, P.; Bernier, M.; de Cabo, R. Overexpression of CYB5R3 and NQO1, two NAD(+) -producing enzymes, mimics aspects of caloric restriction. Aging Cell 2018, 17, e12767.

125. Sontag, E.M.; Samant, R.S.; Frydman, J. Mechanisms and Functions of Spatial Protein Quality Control. Annu Rev Biochem 2017, 86, 97-122.

126. Enam, C.; Geffen, Y.; Ravid, T.; Gardner, R.G. Protein Quality Control Degradation in the Nucleus. Annu Rev Biochem 2018, 87, 725-749.

127. Fang, Q.; Andrews, J.; Sharma, N.; Wilk, A.; Clark, J.; Slyskova, J.; Koczor, C.A.; Lans, H.; Prakash, A.; Sobol, R.W. Stability and sub-cellular localization of DNA polymerase beta is regulated by interactions with NQO1 and XRCC1 in response to oxidative stress. Nucleic Acids Res 2019, 47, 6269-6286.

128. Janke, C.; Montagnac, G. Causes and Consequences of Microtubule Acetylation. Curr Biol 2017, 27, R1287-R1292.

129. Vankova, P.; Salido, E.; Timson, D.J.; Man, P.; Pey, A.L. A dynamic core in human NQO1 controls the functional and stability effects of ligand binding and their communication across the enzyme dimer. Biomolecules 2019, 9, 728 .

130. Lienhart, W.D.; Strandback, E.; Gudipati, V.; Koch, K.; Binter, A.; Uhl, M.K.; Rantasa, D.M.; Bourgeois, B.; Madl, T.; Zangger, K.; Gruber, K.; Macheroux, P. Catalytic competence, structure and stability of the cancer-associated R139W variant of the human NAD(P)H:quinone oxidoreductase 1 (NQO1). FEBS J 2017, 284, 1233-1245.

131. Munoz, I.G.; Morel, B.; Medina-Carmona, E.; Pey, A.L. A mechanism for cancer-associated inactivation of NQO1 due to P187S and its reactivation by the consensus mutation H80R. FEBS Lett 2017, 591, 2826-2835.

132. Pey, A.L.; Megarity, C.F.; Timson, D.J. NAD(P)H quinone oxidoreductase (NQO1): an enzyme which needs just enough mobility, in just the right places. Biosci Rep 2019, 39, BSR20180459.

133. Pey, A.L.; Megarity, C.F.; Timson, D.J. FAD binding overcomes defects in activity and stability displayed by cancer-associated variants of human NQO1. Biochim Biophys Acta 2014, 1842, 2163-2173.

134. Asher, G.; Dym, O.; Tsvetkov, P.; Adler, J.; Shaul, Y. The crystal structure of NAD(P)H quinone oxidoreductase 1 in complex with its potent inhibitor dicoumarol. Biochemistry 2006, 45, 6372-6378.

135. Pey, A.L. unpublished observations.

136. Medina-Carmona, E.; Betancor-Fernández, I.; Santos, J.; Mesa-Torres, N.; Grottelli, S.; Batlle, C.; Naganathan, A.N.; Oppici, O.; Cellini, B.; Ventura, S.; Salido, E.; Pey, A.L. Insight into the specificity and 
severity of pathogenic mechanisms associated with missense mutations through experimental and structural perturbation analyses. Human Molecular Genetics 2019, 28, 1-15.

137. Mesa-Torres, N.; Betancor-Fernández, I.; Oppici, E.; Cellini, B.; Salido, E.; Pey, A.L. Evolutionary Divergent Suppressor Mutations in Conformational Diseases. Genes 2018, 9, E352.

138. Lata, S.; Ali, A.; Sood, V.; Raja, R.; Banerjea, A.C. HIV-1 Rev downregulates Tat expression and viral replication via modulation of $\mathrm{NAD}(\mathrm{P}) \mathrm{H}$ :quinine oxidoreductase 1 (NQO1). Nat Commun 2015, 6, 7244.

139. Moran, J.L.; Siegel, D.; Ross, D. A potential mechanism underlying the increased susceptibility of individuals with a polymorphism in $\mathrm{NAD}(\mathrm{P}) \mathrm{H}$ :quinone oxidoreductase 1 (NQO1) to benzene toxicity. Proc Natl Acad Sci U S A 1999, 96, 8150-8155.

140. Siegel, D.; McGuinness, S.M.; Winski, S.L.; Ross, D. Genotype-phenotype relationships in studies of a polymorphism in NAD(P)H:quinone oxidoreductase 1. Pharmacogenetics 1999, 9, 113-121.

141. Traver, R.D.; Siegel, D.; Beall, H.D.; Phillips, R.M.; Gibson, N.W.; Franklin, W.A.; Ross, D. Characterization of a polymorphism in $\operatorname{NAD}(\mathrm{P}) \mathrm{H}$ : quinone oxidoreductase (DT-diaphorase). Br J Cancer 1997, $75,69-75$.

142. Claveria-Gimeno, R.; Velazquez-Campoy, A.; Pey, A.L. Thermodynamics of cooperative binding of FAD to human NQO1: Implications to understanding cofactor-dependent function and stability of the flavoproteome. Arch Biochem Biophys 2017, 636, 17-27.

143. Asher, G.; Lotem, J.; Kama, R.; Sachs, L.; Shaul, Y. NQO1 stabilizes p53 through a distinct pathway. Proc Natl Acad Sci U S A 2002, 99, 3099-3104.

144. Pan, S.S.; Forrest, G.L.; Akman, S.A.; Hu, L.T. NAD $(\mathrm{P}) \mathrm{H}$ :quinone oxidoreductase expression and mitomycin C resistance developed by human colon cancer HCT 116 cells. Cancer Res 1995, 55, 330-335.

145. Berlow, R.B.; Dyson, H.J.; Wright, P.E. Hypersensitive termination of the hypoxic response by a disordered protein switch. Nature 2017, 543, 447-451.

146. Wang, Y.; Brooks Iii, C.L. Electrostatic Forces Control the Negative Allosteric Regulation in a Disordered Protein Switch. J Phys Chem Lett 2020, 11, 864-868.

147. Garcia-Torres, I.; de la Mora-de la Mora, I.; Marcial-Quino, J.; Gomez-Manzo, S.; Vanoye-Carlo, A.; Navarrete-Vazquez, G.; Colin-Lozano, B.; Gutierrez-Castrellon, P.; Sierra-Palacios, E.; Lopez-Velazquez, G.; Enriquez-Flores, S. Proton pump inhibitors drastically modify triosephosphate isomerase from Giardia lamblia at functional and structural levels, providing molecular leads in the design of new antigiardiasic drugs. Biochim Biophys Acta 2016, 1860, 97-107.

148. Santofimia-Castano, P.; Rizzuti, B.; Pey, A.L.; Soubeyran, P.; Vidal, M.; Urrutia, R.; Iovanna, J.L.; Neira, J.L. Intrinsically disordered chromatin protein NUPR1 binds to the C-terminal region of Polycomb RING1B. Proc Natl Acad Sci U S A 2017, 114, E6332-E6341.

149. Santofimia-Castano, P.; Xia, Y.; Lan, W.; Zhou, Z.; Huang, C.; Peng, L.; Soubeyran, P.; Velazquez-Campoy, A.; Abian, O.; Rizzuti, B.; Neira, J.L.; Iovanna, J. Ligand-based design identifies a potent NUPR1 inhibitor exerting anticancer activity via necroptosis. J Clin Invest 2019, 129, 2500-2513.

150. Nolan, K.A.; Scott, K.A.; Barnes, J.; Doncaster, J.; Whitehead, R.C.; Stratford, I.J. Pharmacological inhibitors of $\mathrm{NAD}(\mathrm{P}) \mathrm{H}$ quinone oxidoreductase, NQO1: structure/activity relationships and functional activity in tumour cells. Biochem Pharmacol 2010, 80, 977-981.

151. Nolan, K.A.; Zhao, H.; Faulder, P.F.; Frenkel, A.D.; Timson, D.J.; Siegel, D.; Ross, D.; Burke, T.R., Jr.; Stratford, I.J.; Bryce, R.A. Coumarin-based inhibitors of human NAD(P)H:quinone oxidoreductase-1. Identification, structure-activity, off-target effects and in vitro human pancreatic cancer toxicity. J Med Chem 2007, 50, 6316-6325.

152. Scott, K.A.; Barnes, J.; Whitehead, R.C.; Stratford, I.J.; Nolan, K.A. Inhibitors of NQO1: identification of compounds more potent than dicoumarol without associated off-target effects. Biochem Pharmacol 2011, 81, 355-363.

153. Asher, G.; Lotem, J.; Cohen, B.; Sachs, L.; Shaul, Y. Regulation of p53 stability and p53-dependent apoptosis by NADH quinone oxidoreductase 1. Proc Natl Acad Sci U S A 2001, 98, 1188-1193.

154. Megarity, C.F.; Abdel-Bettley, H.; Caraher, M.C.; Scott, K.A.; RA, W.; Jowitt, T.A.; Gutierrez, A.; Bryce, R.A.; Nolan, K.A.; Stratford, I.J.; Timson, D. Negative cooperativity in NADP(H) quinone oxidoreductase 1 (NQO1). ChemBioChem 2019, 20:2841-2849, 2841-2849.

155. Lind, C.; Cadenas, E.; Hochstein, P.; Ernster, L. DT-diaphorase: purification, properties, and function. Methods Enzymol. 1990, 186, 287-301.

156. Ernster, L.; Danielson, L.; Ljunggren, M. DT diaphorase. I. Purification from the soluble fraction of rat-liver cytoplasm, and properties. Biochim Biophys Acta 1962, 58, 171-188.

157. Ross, D.; Siegel, D. Functions of NQO1 in Cellular Protection and CoQ10 Metabolism and its Potential Role as a Redox Sensitive Molecular Switch. Front Physiol 2017, 8, 595. 
158. Beyer, R.E.; Segura-Aguilar, J.; Di Bernardo, S.; Cavazzoni, M.; Fato, R.; Fiorentini, D.; Galli, M.C.; Setti, M.; Landi, L.; Lenaz, G. The role of DT-diaphorase in the maintenance of the reduced antioxidant form of coenzyme Q in membrane systems. Proc Natl Acad Sci U S A 1996, 93, 2528-2532.

159. Onyenwoke, R.U.; Wiegel, J. Iron (III) reduction: A novel activity of the human NAD(P)H:oxidoreductase. Biochem Biophys Res Commun 2007, 353, 389-393.

160. Haefeli, R.H.; Erb, M.; Gemperli, A.C.; Robay, D.; Courdier Fruh, I.; Anklin, C.; Dallmann, R.; Gueven, N. NQO1-dependent redox cycling of idebenone: effects on cellular redox potential and energy levels. PLoS One 2011, 6, e17963.

161. Walton, M.I.; Smith, P.J.; Workman, P. The role of NAD(P)H: quinone reductase (EC 1.6.99.2, DT-diaphorase) in the reductive bioactivation of the novel indoloquinone antitumor agent EO9. Cancer Commun 1991, 3, 199-206.

162. Brunmark, A.; Cadenas, E.; Lind, C.; Segura-Aguilar, J.; Ernster, L. DT-diaphorase-catalyzed two-electron reduction of quinone epoxides. Free Radic Biol Med 1987, 3, 181-188.

163. Pink, J.J.; Planchon, S.M.; Tagliarino, C.; Varnes, M.E.; Siegel, D.; Boothman, D.A. NAD(P)H:Quinone oxidoreductase activity is the principal determinant of beta-lapachone cytotoxicity. J Biol Chem 2000, 275, 5416-5424.

164. Silvers, M.A.; Deja, S.; Singh, N.; Egnatchik, R.A.; Sudderth, J.; Luo, X.; Beg, M.S.; Burgess, S.C.; DeBerardinis, R.J.; Boothman, D.A.; Merritt, M.E. The NQO1 bioactivatable drug, beta-lapachone, alters the redox state of NQO1+ pancreatic cancer cells, causing perturbation in central carbon metabolism. J Biol Chem 2017, 292, 18203-18216.

165. Siegel, D.; Gibson, N.W.; Preusch, P.C.; Ross, D. Metabolism of mitomycin C by DT-diaphorase: role in mitomycin C-induced DNA damage and cytotoxicity in human colon carcinoma cells. Cancer Res 1990, 50, 7483-7489.

166. Siegel, D.; Beall, H.; Senekowitsch, C.; Kasai, M.; Arai, H.; Gibson, N.W.; Ross, D. Bioreductive activation of mitomycin C by DT-diaphorase. Biochemistry 1992, 31, 7879-7885.

167. Nemeikaite-Ceniene, A.; Sarlauskas, J.; Jonusiene, V.; Maroziene, A.; Miseviciene, L.; Yantsevich, A.V.; Cenas, N. Kinetics of Flavoenzyme-Catalyzed Reduction of Tirapazamine Derivatives: Implications for Their Prooxidant Cytotoxicity. Int J Mol Sci 2019, 20.

168. Sarlauskas, J.; Miseviciene, L.; Maroziene, A.; Karvelis, L.; Stankeviciute, J.; Krikstopaitis, K.; Cenas, N.; Yantsevich, A.; Laurynenas, A.; Anusevicius, Z. The study of NADPH-dependent flavoenzyme-catalyzed reduction of benzo[1,2-c]1,2,5-oxadiazole N-oxides (benzofuroxans). Int J Mol Sci 2014, 15, 23307-23331.

169. Miseviciene, L.; Anusevicius, Z.; Sarlauskas, J.; Cenas, N. Reduction of nitroaromatic compounds by $\mathrm{NAD}(\mathrm{P}) \mathrm{H}$ :quinone oxidoreductase (NQO1): the role of electron-accepting potency and structural parameters in the substrate specificity. Acta Biochim Pol 2006, 53, 569-576.

170. Sarlauskas, J.; Dickancaite, E.; Nemeikaite, A.; Anusevicius, Z.; Nivinskas, H.; Segura-Aguilar, J.; Cenas, N. Nitrobenzimidazoles as substrates for DT-diaphorase and redox cycling compounds: their enzymatic reactions and cytotoxicity. Arch Biochem Biophys 1997, 346, 219-229.

171. Munoz, P.; Cardenas, S.; Huenchuguala, S.; Briceno, A.; Couve, E.; Paris, I.; Segura-Aguilar, J. DT-Diaphorase Prevents Aminochrome-Induced Alpha-Synuclein Oligomer Formation and Neurotoxicity. Toxicol Sci 2015, 145, 37-47.

172. Graumann, R.; Paris, I.; Martinez-Alvarado, P.; Rumanque, P.; Perez-Pastene, C.; Cardenas, S.P.; Marin, P.; Diaz-Grez, F.; Caviedes, R.; Caviedes, P.; Segura-Aguilar, J. Oxidation of dopamine to aminochrome as a mechanism for neurodegeneration of dopaminergic systems in Parkinson's disease. Possible neuroprotective role of DT-diaphorase. Pol J Pharmacol 2002, 54, 573-579.

173. Hosoda, S.; Nakamura, W.; Hayashi, K. Properties and reaction mechanism of DT diaphorase from rat liver. J Biol Chem 1974, 249, 6416-6423.

174. Rase, B.; Bartfai, T.; Ernster, L. Purification of DT-diaphorase by affinity chromatography. Occurrence of two subunits and nonlinear Dixon and Scatchard plots of the inhibition by anticoagulants. Arch Biochem Biophys 1976, 172, 380-386.

175. Tsvetkov, P.; Asher, G.; Reiss, V.; Shaul, Y.; Sachs, L.; Lotem, J. Inhibition of NAD(P)H:quinone oxidoreductase 1 activity and induction of p53 degradation by the natural phenolic compound curcumin. Proc Natl Acad Sci U S A 2005, 102, 5535-5540.

176. Patino-Morales, C.C.; Soto-Reyes, E.; Arechaga-Ocampo, E.; Ortiz-Sanchez, E.; Antonio-Vejar, V.; Pedraza-Chaverri, J.; Garcia-Carranca, A. Curcumin stabilizes p53 by interaction with NAD(P)H:quinone oxidoreductase 1 in tumor-derived cell lines. Redox Biol 2020, 28, 101320.

177. Megarity, C.F.; Timson, D.J. Cancer-associated variants of human NQO1: impacts on inhibitor binding and cooperativity. Biosci Rep 2019, 39. 
178. Tie, J.K.; Jin, D.Y.; Straight, D.L.; Stafford, D.W. Functional study of the vitamin K cycle in mammalian cells. Blood 2011, 117, 2967-2974.

179. Asher, G.; Lotem, J.; Sachs, L.; Kahana, C.; Shaul, Y. Mdm-2 and ubiquitin-independent p53 proteasomal degradation regulated by NQO1. Proc Natl Acad Sci U S A 2002, 99, 13125-13130.

180. Anwar, A.; Dehn, D.; Siegel, D.; Kepa, J.K.; Tang, L.J.; Pietenpol, J.A.; Ross, D. Interaction of human $\mathrm{NAD}(\mathrm{P}) \mathrm{H}$ :quinone oxidoreductase 1 (NQO1) with the tumor suppressor protein p53 in cells and cell-free systems. J Biol Chem 2003, 278, 10368-10373.

181. Asher, G.; Bercovich, Z.; Tsvetkov, P.; Shaul, Y.; Kahana, C. 20 S proteasomal degradation of ornithine decarboxylase is regulated by NQO1. Mol Cell 2005, 17, 645-655.

182. Zhang, M.; Pickart, C.M.; Coffino, P. Determinants of proteasome recognition of ornithine decarboxylase, a ubiquitin-independent substrate. EMBO J 2003, 22, 1488-1496.

183. Anwar, A.; Siegel, D.; Kepa, J.K.; Ross, D. Interaction of the molecular chaperone Hsp70 with human NAD(P)H:quinone oxidoreductase 1. J Biol Chem 2002, 277, 14060-14067.

184. Tsvetkov, P.; Adamovich, Y.; Elliott, E.; Shaul, Y. E3 ligase STUB1/CHIP regulates NAD(P)H:quinone oxidoreductase 1 (NQO1) accumulation in aged brain, a process impaired in certain Alzheimer disease patients. J Biol Chem 2011, 286, 8839-8845.

185. Adler, J.; Reuven, N.; Kahana, C.; Shaul, Y. c-Fos proteasomal degradation is activated by a default mechanism, and its regulation by $\mathrm{NAD}(\mathrm{P}) \mathrm{H}$ :quinone oxidoreductase 1 determines c-Fos serum response kinetics. Mol Cell Biol 2010, 30, 3767-3778.

186. Chen, Y.; Yang, L.N.; Cheng, L.; Tu, S.; Guo, S.J.; Le, H.Y.; Xiong, Q.; Mo, R.; Li, C.Y.; Jeong, J.S.; Jiang, L.; Blackshaw, S.; Bi, L.J.; Zhu, H.; Tao, S.C.; Ge, F. Bcl2-associated athanogene 3 interactome analysis reveals a new role in modulating proteasome activity. Mol Cell Proteomics 2013, 12, 2804-2819.

187. Garate, M.; Wong, R.P.; Campos, E.I.; Wang, Y.; Li, G. NAD(P)H quinone oxidoreductase 1 inhibits the proteasomal degradation of the tumour suppressor p33(ING1b). EMBO Rep 2008, 9, 576-581.

188. Garate, M.; Campos, E.I.; Bush, J.A.; Xiao, H.; Li, G. Phosphorylation of the tumor suppressor p33(ING1b) at Ser-126 influences its protein stability and proliferation of melanoma cells. FASEB J 2007, 21, 3705-3716.

189. Alard, A.; Fabre, B.; Anesia, R.; Marboeuf, C.; Pierre, P.; Susini, C.; Bousquet, C.; Pyronnet, S. NAD(P)H quinone-oxydoreductase 1 protects eukaryotic translation initiation factor 4GI from degradation by the proteasome. Mol Cell Biol 2010, 30, 1097-1105.

190. Maeda, T.; Tanabe-Fujimura, C.; Fujita, Y.; Abe, C.; Nanakida, Y.; Zou, K.; Liu, J.; Liu, S.; Nakajima, T.; Komano, H. NAD $(\mathrm{P}) \mathrm{H}$ quinone oxidoreductase 1 inhibits the proteasomal degradation of homocysteine-induced endoplasmic reticulum protein. Biochem Biophys Res Commun 2016, 473, 1276-1280.

191. Hori, O.; Ichinoda, F.; Yamaguchi, A.; Tamatani, T.; Taniguchi, M.; Koyama, Y.; Katayama, T.; Tohyama, M.; Stern, D.M.; Ozawa, K.; Kitao, Y.; Ogawa, S. Role of Herp in the endoplasmic reticulum stress response. Genes Cells 2004, 9, 457-469.

192. Adamovich, Y.; Shlomai, A.; Tsvetkov, P.; Umansky, K.B.; Reuven, N.; Estall, J.L.; Spiegelman, B.M.; Shaul, Y. The protein level of PGC-1alpha, a key metabolic regulator, is controlled by NADH-NQO1. Mol Cell Biol 2013, 33, 2603-2613.

193. Guryanova, O.A.; Drazba, J.A.; Frolova, E.I.; Chumakov, P.M. Actin cytoskeleton remodeling by the alternatively spliced isoform of PDLIM4/RIL protein. J Biol Chem 2011, 286, 26849-26859.

194. Hershkovitz Rokah, O.; Shpilberg, O.; Granot, G. NAD(P)H quinone oxidoreductase protects TAp63gamma from proteasomal degradation and regulates TAp63gamma-dependent growth arrest. PLoS One 2010, 5, e11401. 